University of Warwick institutional repository: http://go.warwick.ac.uk/wrap

This paper is made available online in accordance with publisher policies.

Please scroll down to view the document itself. Please refer to the repository record for this item and our policy information available from the repository home page for further information.

To see the final version of this paper please visit the publisher's website. Access to the published version may require a subscription.

Author(s): Michael Waterson, Monica Giulietti, Jesus Otero

Article Title: Pricing behaviour under competition in the UK electricity supply industry

Year of publication: 2007

Link to published version:

http://www2.warwick.ac.uk/fac/soc/economics/research/papers/twerp_ 790.pdf 
Pricing behaviour under competition in the UK electricity supply industry

No 790

WARWICK ECONOMIC RESEARCH PAPERS

DEPARTMENT OF ECONOMICS

THE UNIVERSITY OF

WARWICK 


\title{
Pricing behaviour under competition in the UK electricity supply industry *
}

\author{
Monica Giulietti \\ Aston Business School \\ Aston University \\ United Kingdom
}

\author{
Jesús Otero \\ Facultad de Economía \\ Universidad del Rosario \\ Colombia
}

\author{
Michael Waterson \\ Department of Economics \\ University of Warwick \\ United Kingdom
}

January 2007

\begin{abstract}
This paper investigates the evolution of electricity prices for domestic customers in the UK following the introduction of competition. The empirical analysis is based on a panel data set containing detailed information about electricity supply prices over the period 1999 to 2006 . The analysis aims to test theoretical hypotheses about the nature of consumers' switching and search costs. The econometric analysis of persistence and price dispersion provides only limited support for the view that the market is becoming more competitive and also indicates that there remain significant potential benefits to consumers from searching alternative suppliers.
\end{abstract}

Keywords: electricity supply, price competition, convergence, dynamic panels, crosssectional dependency.

JEL classification: L43, L13, L94, C22, C23

\footnotetext{
${ }^{*}$ We are grateful to the various people who have updated the pricing dataset over time. Initial data collection was made possible by Leverhulme grant F215/AX to the Centre for Management Under Regulation, University of Warwick. We also acknowledge financial support from the ESRC Grant RES-000-22-1686. Part of this paper was written while the second-named author was a Visiting Fellow in the Department of Economics at the University of Warwick. He would like to thank the Universidad del Rosario for its financial assistance.
} 


\section{Introduction}

Competition in UK energy supply has arguably proceeded further than in any other country. Not only have all UK consumers been able to choose their electricity supplier since May 1999 and very significant numbers have done so, but also since March 2002 there has been no supply price regulation. Therefore, an experiment of international significance is taking place, concerning the behaviour of consumers and their suppliers in relation to a key product. As one manifestation of this, firms from many other countries are participating in the market in order to gain experience of live competition at work; US, German and French firms have taken significant stakes in the UK supply industry.

The focus of this paper is on the development over time of tariff structures for supply to domestic customers. Here, one null hypothesis would be that, as a result of competition, prices for such a homogeneous product converge together quickly. An alternative is that prices would remain somewhat dispersed, as a consequence of firms exploiting significant search and switching costs and creating product differentiation. Under this alternative, we might expect that particular events would trigger changes in the distribution of prices; for example the freeing of a particular class of consumers from price regulation, or input price changes arising from changes in supply source (e.g. in 2004 the UK started importing gas from Norway) may have influenced the price vector consumers face. By examining the pattern of prices and changes in this pattern over time, we aim to tease out information about the influence of search costs and switching costs and the extent to which the market is or is becoming competitive in practice.

As a background to this study, we should note a number of important institutional features that facilitate the development of competition in the market in question. When the electricity market was broken up into generation, transmission, distribution and supply, the link between supply and distribution was broken. Transmission and distribution remain regulated, but any competent potential supplier may obtain a licence. Thus, by knowing the (regulated) prices for transport, and by writing contracts for wholesale electricity, a supplier is enabled to design a tariff to attract consumers away from their incumbent supplier. Ancillary services, such as meter reading, may also be purchased on the market, but suppliers retain responsibility for billing, in a single bill to cover all vertical levels. A standardised system of identifying customers by their meter number facilitates their accurate transfer between suppliers. 
As industry regulator, OFGEM is charged with overseeing the development of competition. Energywatch, a related body, has a duty to provide consumers with information regarding suppliers. Amongst other measures, they discharge this duty by providing regularly updated price comparison sheets on their website, covering every active supplier. In addition, they provide qualitative comparative information such as numbers of complaints about particular suppliers. Commercial companies may also provide price comparison services, so long as these cover the market and do not favour suppliers selectively, and this has developed into a significant business with several such services active currently. They provide facilities to "click through" in order to switch supplier through their intermediation (indeed, this is the means by which they make money). The typical consumer is thus able to make an informed choice amongst around ten suppliers. However, all the major companies also engage in their own marketing activity, commonly using a sales force that moves from door to door within an area. The sales pitch focuses on price, with a secondary emphasis on service (but in both cases tends to be rather unspecific). At time of writing, almost half of all customers are supplied by a firm that is not their incumbent supplier. ${ }^{1}$

The competitors in electricity supply are of three main types. Before liberalisation, supply was a regionally-based activity, and prices generally differ as between the 14 regions still (costs also differ, as a result of transport cost differences). ${ }^{2}$ Thus one category of competition comes from suppliers extending their activities across regions (usually, maintaining a differential in prices). A second category comes from companies engaged previously in the supply of gas. Prime amongst these is British (in Scotland, trading as Scottish) Gas, which provided a national integrated service for the supply of gas, but other gas supply companies, some associated in part with oil companies, also entered the electricity market. ${ }^{3}$ The third force is independent suppliers; contrary to some expectations, these have tended not to be companies with a strong knowledge of mass market consumer activity or billing.

Our period of analysis runs from February 1999 to December 2006, spanning eight years of price data. During the sample period important strategic and institutional changes in electricity prices have occurred. For example, in April 2002 the energy regulator, OFGEM, removed all price controls for all residential consumers. Furthermore, perhaps as early as the Spring of 2002 we observed a worldwide trend of increasing oil and fuel costs which was

\footnotetext{
${ }^{1}$ The gross rate of switching is higher, because some people switch back.

${ }^{2}$ That is, the price you can buy at depends upon where you live, i.e. your postcode.

${ }^{3}$ The gas market was opened to competition earlier. In some ways, though, it is less interesting analytically, since it is national not regional in nature, so that there is less variation to observe. British Gas remains the most important operator in the gas market.
} 
reflected in substantial increases in fuel costs in the UK. The potential impact of these changes is taken into account in our empirical analysis.

Besides differentiation by area, scope exists for companies to differentiate between various broad classes of customer. There are three main ways of paying bills, namely by (monthly) direct debit, by quarterly bill (paid in arrears) and by prepayment meter. These involve different supply costs, direct debit being the cheapest and prepayment the most expensive. Since all suppliers' tariffs are at least two-part, companies can also differentiate between low and high consumers of electricity. ${ }^{4}$ There is also a distinction between completely online offerings and tariffs that are available to consumers signing up through a range of possible approaches.

In the last few years, with the growth of the internet as a means for consumer purchases, there has been considerable interest amongst economists concerning the role it may play in reducing the impact of search costs on consumer purchases and therefore perhaps on reducing the variance in prices consumers may encounter and on making markets more competitive. ${ }^{5}$ This study is unique in examining the effect on prices as the market under study is opened up to competition, in a context where a complete listing of prices is available on the internet. Thus additional quotes are available to internet users at zero additional charge. It is also relevant to note that shipping costs, which complicate or even bedevil price comparisons in other areas, are always included in this case. The savings from shopping around can be, though are not always, considerable.

The paper proceeds as follows. We start by developing testable hypotheses in section 2 , followed by a description of the data and the econometric procedure used in the empirical analysis in section 3. Section 4 contains a discussion of the main results while section 5 offers some concluding remarks.

\footnotetext{
${ }^{4}$ In this paper we are concerned only with domestic consumers. Pricing to other consumers is not transparent to the outside observer. We also will not consider at present "dual fuel" deals and the (increasingly less important) "Economy 7" tariffs; see Green (2005) on dual fuel.

${ }^{5}$ See e.g. Ellison and Ellison (2005) for a thoughtful survey.
} 


\section{Hypotheses}

The switch that we are concerned with here is from an incumbent to an entrant player in the market. Pro-competitive actions by the regulator have facilitated the switching process, but studies of consumers (e.g. Giulietti et. al, 2005) have shown that nevertheless, some consumers remain reluctant to switch, even in the face of substantial financial benefits. The incumbent can therefore charge a premium over entrant suppliers without losing all its custom, and it faces a trade-off between a higher premium, with fewer customer retentions, and a lower premium, retaining more customers. We wish to examine the time path of the premia that incumbents can maintain, later to make comparisons with what consumers say they do, or will do.

Our underlying assumption in this analysis is that firms set prices conscious of consumer reactions; they will need to assess the competitiveness of their tariffs and adjust them over time in response to consumer behaviour in order to capture a segment of the market. Thus tariffs reveal firms' views about the nature of the market. ${ }^{6}$ At its most basic, a new player who charges a price above an incumbent supplier cannot hope to gain customers. More relevant is the decision by an entrant as to how much to shade price below the incumbent. This will depend upon the firm's evaluation of search and switching behaviour, together with its expectations about the behaviour of other suppliers. We also assume that within an area, for each class of consumer, costs are the same for each player save the incumbent.

The consumer behaviour with which we are concerned is the switch from their incumbent supplier to another supplier. Changing electricity supplier involves both search costs and switching costs. Divergences in price between the incumbent and others thus reflect both search and switching costs. However, divergences in prices between non-incumbent suppliers will we assume reflect search cost influences, not switching cost influences.

The basis of our analysis is that we may separate observed pricing divergences into two parts. The presence of divergences between non-incumbent suppliers' prices can be related solely to search cost phenomena (by design of the market), so we analyse these within a search cost framework. We then analyse the switching cost element by reducing to a minimum the

\footnotetext{
${ }^{6}$ We know from earlier work on consumer behaviour (Giulietti et al, 2005) that consumers do perceive substantial switching costs between incumbent and entrant.
} 
degree of search when focusing on divergences between incumbents' and non-incumbents' prices.

Our method of separating the two phenomena involves a split at the median non-incumbent's price. The distance between median price, the price that would on average be achieved by making a single price enquiry, and the lowest price, which would be revealed by a complete search, is our basic measure of search costs (we also examine the range of prices). So far as switching is concerned, the gap between incumbent price and median price is arguably the nearest we can get to the switching cost, since it represents the difference between the incumbent's price and the average price that would be obtained by switching to a random other supplier.

The search cost literature, following Burdett and Judd (1983) and Stahl (1989), commonly assumes that some consumers are uninformed and face positive search costs for each additional search whilst (at least in Stahl) a subset of consumers is assumed to be fully informed. This leads to equilibria in which there is price dispersion. Stahl shows that as the proportion of customers with complete information increases, the price distribution shifts downward, so improvement in consumers' average information levels reduces average prices and, possibly, prices for the uninformed consumers, making the market more competitive. Thus, if search costs are negligible, non-incumbents will all set the same price. If not, search cost theory suggests that price dispersion will remain and that the identity of the lowest price suppliers will change over time (Varian, 1980; Baye and Morgan, 2001). This leads to the prediction that increased internet usage will make markets more competitive, ${ }^{7}$ although it need not reduce price dispersion.

Also relevant is whether an increase in the number of suppliers has an influence on the average price paid/offered. Here there are two forces and predictions depend quite delicately upon the nature of the model (see Janssen and Moraga-González, 2004). Consider the position as firms enter. The "business stealing" effect of charging lower prices to capture more consumers strengthens, but so too does the "surplus appropriation" effect of earning a high surplus from uninformed consumers. Morgan et al (2006) find that as the number of firms increases, informed customers pay lower prices whilst the uninformed face higher prices.

\footnotetext{
${ }^{7}$ Janssen and Moraga-González (2004) argue that in what they term "low search intensity equilibria", this result does not hold. Examining relative magnitudes suggests that these are unlikely in our case.
} 
Empirically, although results are somewhat mixed, Brown and Goolsbee (2002) for example have convincingly shown that the introduction of internet trading for term life insurance reduced premiums on average, by a significant $8-15 \%$. However in this case, dispersion initially increased.

In the present context, access to information via the internet can be argued to have increased significantly over time. For example, the National Statistics Omnibus Survey reports that whilst in the three months to October 2000 (the earliest date listed), 36\% of consumers used the internet for buying or ordering goods or services, by 2006 over $60 \%$ did. The proportion of people using it to find information about goods and services rose from $70 \%$ to nearly $90 \%$ over the same period. The proportion of consumers connected to the internet rose $38 \%$ between March 2001 (the earliest date given) and March 2006, and whilst essentially all were on dialup connection in 2001, over 70\% were on broadband connection in 2006.

Fast internet access brings with it the possibility of searching all suppliers at once in a manner tailored to one's own consumption through one of the many comparison sites, together with click-through to the chosen site. Hence, if a large proportion of consumers avail themselves of this opportunity, the search literature would suggest that average prices will fall, and eventually price dispersion would decrease also. However there is evidence (OFGEM, 2004) that although the proportion of searchers using the internet specifically for this purpose has increased over time, from $4 \%$ in 2001 to $10 \%$ in 2003, it is still a minority method of gaining information compared, for example, with information gathered from a representative who called at the consumer's home (see OFGEM; 2004, Table 2.16). Therefore the outcome remains an open question.

Given the analysis above, if the internet, or another mechanism, has made a proportion of people better informed over the period we study, the reduction in average price would have the effect of narrowing the gap, ML, between median and lowest price over time. Another relevant statistic is HL, the range between the highest non-incumbent price and the lowest. In this market, all prices will be actively used in transactions and the number of consumers is very large compared with the number of prices on offer. Hence the range of prices from largest to smallest, HL, offered by non-incumbents is relevant in measuring price dispersion. Some theories would predict dispersion should fall as consumers become more 
knowledgeable, others view dispersion as non-monotonic in the proportion of people with full information.

To summarise, our hypotheses regarding the development of non-incumbent prices are that under convergence ${ }^{8}, \mathrm{ML}$ and perhaps HL will shrink over time, whereas under persistence ${ }^{9}$, ML will not show a clear pattern over time and HL will not shrink.

We now turn to the link between the incumbent's price and the other prices on offer. Since the first set of hypotheses relates to search theory, we wish to link the second set with switching, whilst minimising the impact of search activity on the results. A minimal search would consist of choosing one alternative company to the incumbent at random. If switching costs are miniscule, then a divergence between these prices would cause a minimal searcher to switch. On the other hand, if they are large, then a significant divergence would still fail to persuade someone who has carried out minimal searching to switch supplier. Incumbents, of course, face a trade-off between setting high prices relative to non-incumbents, thereby earning healthy margins, and those high prices driving some consumers away. ${ }^{10}$

Given our floor for the switching element as minimal search, the difference, IM, between the incumbent's price and the median non-incumbent price becomes the statistic of interest in examining perceived switching costs over time. If as a result of observing others' experiences, consumers who have not yet switched perceive switching costs as falling over time (that is, if people see how easy switching in fact is), then IM will fall over time. ${ }^{11}$ On the other hand, if consumers as a group face psychic costs of switching that are arrayed on a distribution, we may conjecture that those with the lowest perceived switching costs switch first and others do not switch because they perceive the costs as too high. If this is so, then after the process has been underway for some time, the average switching cost for those that remain is higher than that in the population of consumers as a whole. In this latter case, companies seeking to gain share at the expense of the incumbent face having to provide increasingly attractive offers over time to capture increasingly intransigent consumers. This alternative predicts that IM increases over time, yielding a benefit to incumbents.

\footnotetext{
${ }^{8}$ We use the term "convergence" in the sense of Baye and Morgan (2001), to mean prices moving towards each other. An alternative terminology is to use convergence to mean stationarity in the time series econometric sense of reverting to a particular value after a shock. We will attempt to distinguish by calling the latter stationarity, but in our empirical work we take account of both.

${ }^{9}$ Persistence is used here in the sense of an antonym of convergence as defined.

${ }^{10}$ This trade-off is explored in Giulietti et al (2005).

${ }^{11}$ See Battisti et al. (2006) for a discussion of the role of "word-of-mouth" in promoting (or encouraging) switching behaviour in the UK residential gas market.
} 
Finally, rather than making a search at random, another alternative would be that the consumer decides to switch to British Gas (BG) as a provider. BG is the best-known provider of energy and has engaged in extensive national promotional campaigns. Thus, a majority of consumers, who do not carry out active search, should be aware that BG is an opportunity. Therefore, as an alternative to the above, we can define the difference IB, between the incumbent's price and BG's. Our hypotheses are therefore that if switching costs fall (rise) over time, IM and IB will fall (rise).

\section{Data and econometric procedure}

\subsection{Data}

Our analysis of the changes in electricity retail prices since the introduction of competition takes into account geographical, product market and temporal dimensions. Our data set consists of a balanced panel of 48 bimonthly price observations for each firm active in the market over the period February 1999 to December 2006. Over this period the number of firms operating in the market ranges between 18 and 6 suppliers. Data were obtained from the Consumer's Association website initially and, later, from the OFGEM and Energywatch websites. All price offers by suppliers are public, in this industry.

As discussed before, electricity retail prices for domestic consumption in the UK differ by payment method and geographical location. As a result of this, our data set comprises 84 cross-sectional units corresponding to the fourteen supply regions ${ }^{12}$, three payment methods namely direct debit (DD), quarterly bills (QB) and prepayment meters (PP), and two levels of consumption, namely high $(\mathrm{H})$ and low $(\mathrm{L})$. We distinguish between high $(4950 \mathrm{KWh}$ per year) and low (1650 KWh per year) consumption in order to reflect the at least two-part nature (generally comprising a standing charge and a unit rate) of electricity tariffs. This allows us to consider six different products whose prices are set by residential energy suppliers. All the companies for which data have been collected and all the tariffs they offered (including internet-only tariffs) are used in the calculation of the variables ML, HL, IM, and IB. In order to construct these variables for our analysis we calculated average yearly bills for

\footnotetext{
12 These regions are Eastern (EA), East Midlands (EM), London (LD), Midlands (MD), Manweb - Greater Manchester (MW), Northern (NT), North Western (NW), South Eastern (SE), Scottish Hydro - North of Scotland (SH), Scottish Power - Southern Scotland(SP), Southern (ST), South Wales (SA), South West (SW) and Yorkshire (YK).
} 
customers on low and high consumption levels for each of the main types of payment methods.

Some sample illustrative charts are shown in Figures 1 to 4 , based on data at the national level. The price pattern observed at the regional level, however, is not dissimilar to the one observed at the national level. These charts all relate to one particular class of consumer, namely direct debit consumers. However, they are enough to show that a simple pattern of convergence to a single price does not exist.

We test our hypotheses by examining the time trends in the series ML, HL, IM and IB. A positive and significant time coefficient on, say, ML, would suggest rejecting the hypothesis that average price is declining over time as a result of increased internet usage However, in order to do so, we first need to examine whether a trend can legitimately be identified.

\subsection{Stationarity}

In testing our hypotheses concerning the evolution of electricity tariffs in the eight years since the introduction of competition we need to incorporate the approach in the literature on convergence to the 'law of one price'. Here several empirical tests of price convergence (what we refer to as stationarity) have been carried out, particularly in the international trade area (Frankel and Rose, 1996), but also with reference to consumer price indices across US cities (Cecchetti et al., 2002,) and car prices across European countries (Goldberg and Verboven, 2005).

Recent contributions in these areas rely on the econometric theory of unit root testing in order to provide evidence of the convergence of prices to a 'common' average in the sense of mean reversion. A number of alternative procedures have recently been proposed to test for the presence of unit roots in dynamic heterogeneous panels, see for example, Im, Pesaran and Shin (2003) and Maddala and Wu (1999). These authors test the null hypothesis of a unit root against the alternative of a least one stationary series, by using the (Augmented) DickeyFuller (ADF) statistic across the cross-sectional units of the panel.

By contrast, Hadri (2000) proposed an $L M$ procedure to test the null hypothesis that the individual observed series are stationary, either around a mean or around a trend, against the alternative of a unit root in the panel. These tests are denoted $Z_{\mu}$ and $Z_{\tau}$, respectively. The 
$L M$ tests proposed by Hadri (2000) are the panel version of the test developed by Kwiattowski et al (KPSS) (1992). The Monte Carlo experiments of Hadri (2000) demonstrate that these tests have good size properties for $T$ and $N$ sufficiently large. However, Giulietti et al. (2006) show that even for relatively large $T$ and $N$ the Hadri (2000) tests suffer from severe size distortions in the presence of cross-sectional dependence, the magnitude of which increases as the strength of the cross-sectional dependence increases. This finding is in line with the results obtained by Strauss and Yigit (2003) and Pesaran (2007) on both the Im, Pesaran and Shin and the Maddala and Wu panel unit root tests. In order to correct the size distortion caused by cross-sectional dependence, Giulietti et al. (2006) apply the bootstrap method and find that the bootstrap Hadri tests are approximately correctly sized.

To implement the bootstrap method in the context of the Hadri tests, we start off by resampling the residuals from either a regression of $y_{i}$ on a constant for the $Z_{\mu}$ test, or on a constant and a trend for the $Z_{\tau}$ test. As suggested by Maddala and Wu (1999, p.646), we resample the residuals with the cross-section index fixed, so that we preserve the crosscorrelation structure of the error term.

With time dependent data, a further refinement in the bootstrap described above can be obtained by applying the idea of bootstrapping overlapping blocks of residuals rather than the individual residuals, also known as the moving block bootstrap approach. ${ }^{13}$ This approach requires the researcher to choose the block size, i.e. the number of contiguous residuals to be resampled with replacement. The choice of the block size is based on the values suggested by the inspection of the correlogram of the series, which involves identifying the smallest integer after which the correlogram becomes negligible, as suggested by Künsch (1989; p.1226). In particular, the results shown in Table 1 are based on 1,000 bootstrap replications used to derive the empirical distribution of the $Z_{\tau}$ statistics, for alternative block sizes of 4,6 and 8 bi-monthly residuals. Although the smallest integer we identified is around four, we also allowed for larger blocks in order to ensure the robustness of the results for longer block sizes.

\footnotetext{
${ }^{13}$ For a discussion of the moving block bootstrap see Künsch (1989), Maddala and Kim (1998) and Berkowitz and Kilian (2000). Lee and Wu (2001) use this approach within the context of the Im, Pesaran and Shin panel unit root test. Details on the implementation of the moving block bootstrap can be found in these references, and so are not presented here to save space.
} 
During the sample period covered in our analysis, an important institutional change in price setting was introduced in April 2002, when the energy regulator, OFGEM, removed all price controls for residential consumers. Furthermore, starting from the Spring in 2002 we observe a substantial increase in fuel costs as illustrated in Figure 5. Thus, to account for the potential impact of these changes for our empirical analysis, the dataset is split into two periods- before and after April 2002.

Applying the Hadri tests for panel stationarity to our dataset over the two sample periods, we find that all the series analysed are stationary around a trend, independently of the selected block size, as reported in Table 1. Given this result, we now turn attention to our main hypotheses.

\subsection{Econometric Approach}

Our four estimating equations have the following form:

$$
\Delta Y_{r p c, t}=\alpha_{r p c}+\alpha_{r p c} * T r+\beta Y_{r p c, t-1}+\sum_{k=1}^{K} \gamma_{l} \Delta Y_{r p c, t-k}+\vartheta N F I R M S_{r, t}+\varepsilon_{r p c, t}
$$

where $Y$ refers to the variables ML, HL, IM, IB relating to the hypotheses developed in section 2, while $r, p, c$ and $t$ identify a region, product, consumption level and time period, respectively. $\Delta$ indicates the first difference operator, so that $\Delta Y_{r p c, t}=Y_{r p c, t}-Y_{r p c, t-1}$. The first $K$ differences in the lagged dependent variable are included to account for potential serial correlation in the error term. The inclusion of five lags of these first differences reduces the number of available time observations to be used for estimation to 42 , so that the total number of observations available is $3528(T=42, N=84), 1512$ of which are used for estimation during the first sample period (February 1999 to April 2002), while the remaining 2016 observations are used for the second sample period (June 2002 to December 2006). ${ }^{14}$

The specification in (1) allows us to assess the speed of any process of reversion to a trend based on the sign and size of the estimated $\beta$ coefficient, keeping in mind that we expect to observe a negative sign for $\beta$ if the process is stationary, while $\beta=0$ indicates that the effect of a shock on prices is permanent. The estimated value of $\beta$ can be used to calculate the approximate half-life of a shock on the dependent variable, based on the formula $-\ln (2) / \beta$.

\footnotetext{
${ }^{14}$ The choice of five lags results from a selection process based on the significance level of relevant $\gamma$ coefficients, having started with $K=6$.
} 
In order to control for region and product-specific factors that might affect the companies' pricing behaviour, regional, product and consumption level dummies $\left(\alpha_{r p c}\right)$ are included in the estimating equation. Furthermore, the inclusion in equation (1) of the number of firms operating in the different regional markets $\left(N F I R M S_{r, t}\right)$, which varies by region and time only, is aimed at controlling for the effects of changes in market structure and the nature of competition as firms enter or exit the market.

However, for the purpose of our analysis of price dispersion over time, the sign and magnitude of the coefficients associated with the interactions between fixed effects (the $\alpha$ 's) and the time trend $T r$ are the most relevant, because they allow us to test the various hypotheses about the presence or lack of convergence in the sense discussed in the previous section. ${ }^{15}$ The presence of a significant positive (negative) deterministic trend term would provide evidence in support of an increasing (decreasing) gap or range (ML or HL) in average bills over time for different regions, products and consumption levels, reflecting the underlying evolution of consumers' search costs as a result of competition. At the same time, the presence of a deterministic trend in the bill differentials between the median nonincumbent supplier or British Gas and the incumbent (IM or IB) allows us to describe the evolution of customers' switching costs in this market and its estimated variation over time.

All the equations are estimated using the Least Squares Dummy Variable estimator that has been shown to provide efficient and unbiased estimates for balanced panels of dimensions close to ours (Judson and Owen, 1999). As mentioned earlier we also include five lags of the dependent variable to account for potential residual serial correlation. The $t$-statistics calculated for all the estimated coefficients are based on White's heteroskedasticity-consistent standard errors and covariances.

\section{Discussion of results}

Our empirical analysis starts by considering fairly general specifications of equation (1) explaining price dynamics. As indicated earlier, the detailed information available about electricity prices allows us to distinguish between the movements of prices across geographical, payment method and consumption level dimensions. In order to account for all

\footnotetext{
${ }^{15}$ Alternative approaches to test price dispersion in the presence of search costs, applying maximum likelihood estimation techniques on price data alone, have been considered recently by Hung and Shum (2006) and Moraga-González and Wildenbeest (2006).
} 
the possible sources of cross-sectional variation in the trend we considered all possible interactions between the different cross-sectional dimensions. The coefficients on the interaction between the time trend and the fixed effects give an indication of the gradual movement of our indexes of price dispersion over time- recall that a significantly negative (positive) trend means that prices are converging (diverging). The most general specification is reported in Appendix 1 and is referred to as the unrestricted model. Based on the results from the stationarity tests reported in Table 1, the unrestricted model is estimated over two sample periods, before and after June 2002. Splitting the sample period in such a way allows us to deal with stationary series and at the same time to account for the potential effect of exogenous changes due to the international markets and institutional changes mentioned earlier.

To assess variability across the fourteen electricity regions, we carried out a series of Wald tests on the estimated coefficients from the unrestricted models of Appendix 1. The results are reported in Table 2. Independently of the sample period, for low consumption users we do not observe statistically significant regional differences in the tariffs for all payment methods, as the Wald tests for the null hypothesis that the estimated coefficients are the same across regions are not rejected (see lines 4 to $6,8,13$ to 15 and 17). Furthermore, for the sample period until April 2002 the hypothesis that the estimated coefficients are not significantly different between tariffs for high and low consumption levels (line 9) is not rejected for all payment methods. The corresponding hypothesis for the sample period starting in June 2002 is rejected, at least at the $10 \%$ significance level (line 18). Focussing again on the second sample period, for high consumption users the Wald tests reveal regional variations in the estimated coefficients referring to the switching cost variables but not to the search cost variables (see lines 10 to 12 ).

Based on the previous hypotheses tests, we have proceeded to estimate a restricted version of the model, where we make no distinction between high and low levels of consumption. The chosen specification is such that all four dependent variables are regressed on the same set of regressors. The resulting restricted models for the two sample periods are reported in Tables 3 and 4, respectively. There is a remarkable concordance on the results within each table.

The results in Table 3, for the first sample period, indicate negative and statistically significant trend coefficients across all regions for $\mathrm{DD}$ and $\mathrm{QB}$, but not for $\mathrm{PP}$, when we consider the variables related to search costs (i.e. ML and HL). On the other hand, the 
variables related to switching costs (i.e. IM and IB) reveal a positive and statistically significant trend across all regions and payment methods. The implication is that search costs were falling in the first period, as we might expect, whilst switching costs were rising, perhaps because those consumers who were switching were increasingly reluctant switchers.

The results presented in Table 4 for the second sample period show that the negative trend in search costs becomes positive and statistically significant across regions and payment methods, while the positive trend in switching costs becomes negative and statistically significant across regions and payment methods. The first result may be due to suppliers becoming more successful in differentiating their products from other suppliers, so that the search takes on less of a commodity nature, whereas the switching cost result may arise because consumers are becoming more used to switching. In neither sub-sample do both search and switching costs decline, so throughout the period there is no monotonic increase in competitiveness amongst suppliers.

The general trend in the price indexes of interest is also partly reflected in the estimated effect of changes in market structure, measured here by the number of firms operating in the market. Throughout the period under examination, (non-incumbent) firm numbers have been declining regularly. The estimated positive coefficients on the number of firms for ML and HL over the two sample periods seem to indicate that as the number of firms reduces, search costs decline. On the other hand, for the second part of the sample only we estimate a significantly negative coefficient on firm numbers for IM and IB, which indicates that the measure of switching costs has been rising since numbers of potential rivals in the second sample period is much smaller than in the first sample period.

Finally, it is of some interest to discuss the variables' speed of adjustment to exogenous shocks or innovations, which involves examining the estimates of the coefficient $\beta$ from (1). Our results in Table 3 and 4 indicate that all the variables analysed are trend stationary processes. The estimated convergence coefficients all have negative sign and are significantly different from zero, as required for convergence. The speed of convergence is relatively slow in the first period, as indicated by estimated coefficients ranging from -0.07 to -0.27 , implying a half life ranging from 20 to 3 months. In the second period the speed of convergence is slightly faster, as the estimated coefficients range from -0.11 to -0.40 , resulting in a half life ranging from 12 to 4 months. 


\section{Conclusions}

On one view, electricity supply is a homogeneous good market in which consumers quickly learn through their own or others' experience how easy it is to switch suppliers in order to save money. As a result, companies aiming to capture new business would need to price competitively and companies wanting to retain business would need to ensure their offer did not move too far out of line with entrants' offers. Hence as companies learnt more about their competitors' moves, differences in the trend values of prices would tend to shrink. To some extent this has happened in the UK, but although a large proportion of consumers has switched there has so far been no comprehensive, substantive analysis of the prices consumers face. By separating the difference between the incumbent's price and entrants' prices into two elements either side of the median non-incumbent price, we obtain approximate measures of search and of switching costs. The surprising findings are how resistant high incumbent prices are to change, and how it remains worthwhile for some nonincumbent suppliers to quote, and do business at, prices that are significantly noncompetitive, in the face of evidence that internet usage has increased significantly over time.

Of course, during the first half of the sample period we are observing, price controls were operative on incumbent players. However removal of these controls has, if anything, led to the gains from switching supplier away from the incumbent to grow over time. Thus, whilst the market has not seen major anticompetitive moves by established players by any means, nor has a fully competitive market emerged. This conclusion is reinforced by the fact that retail electricity prices overall did not fall to the extent of price falls in wholesale prices over the period since a market has developed (OFGEM, 2003), and much more recently have not fallen in line with the falling wholesale prices that followed the substantial hike in 2005-06. 
Figure 1. Difference between median and lowest bills - Direct Debit



Figure 2. Bill range (excluding incumbent) - Direct Debit

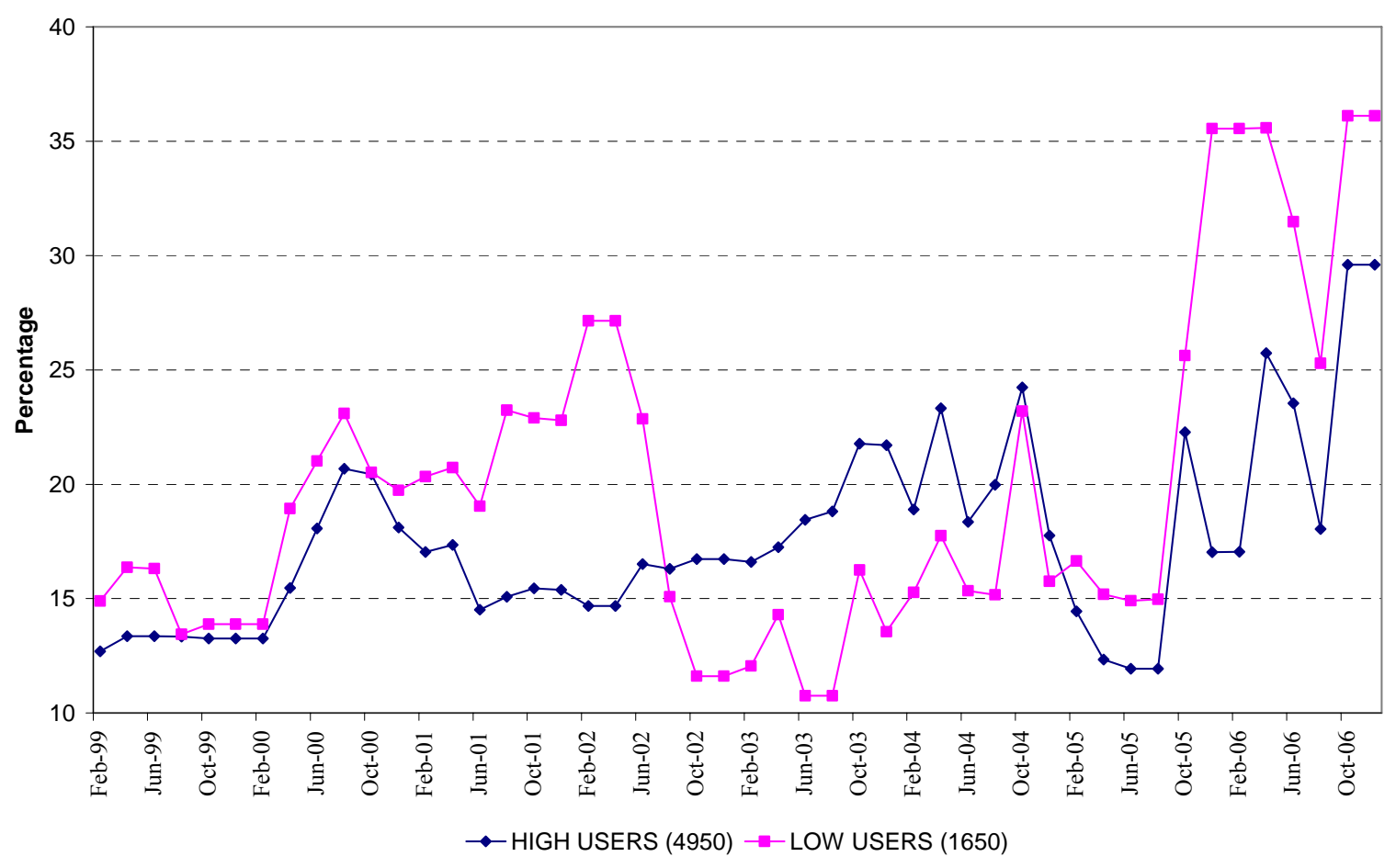


Figure 3. Gain from switching - Direct Debit high users (4950 KWh)

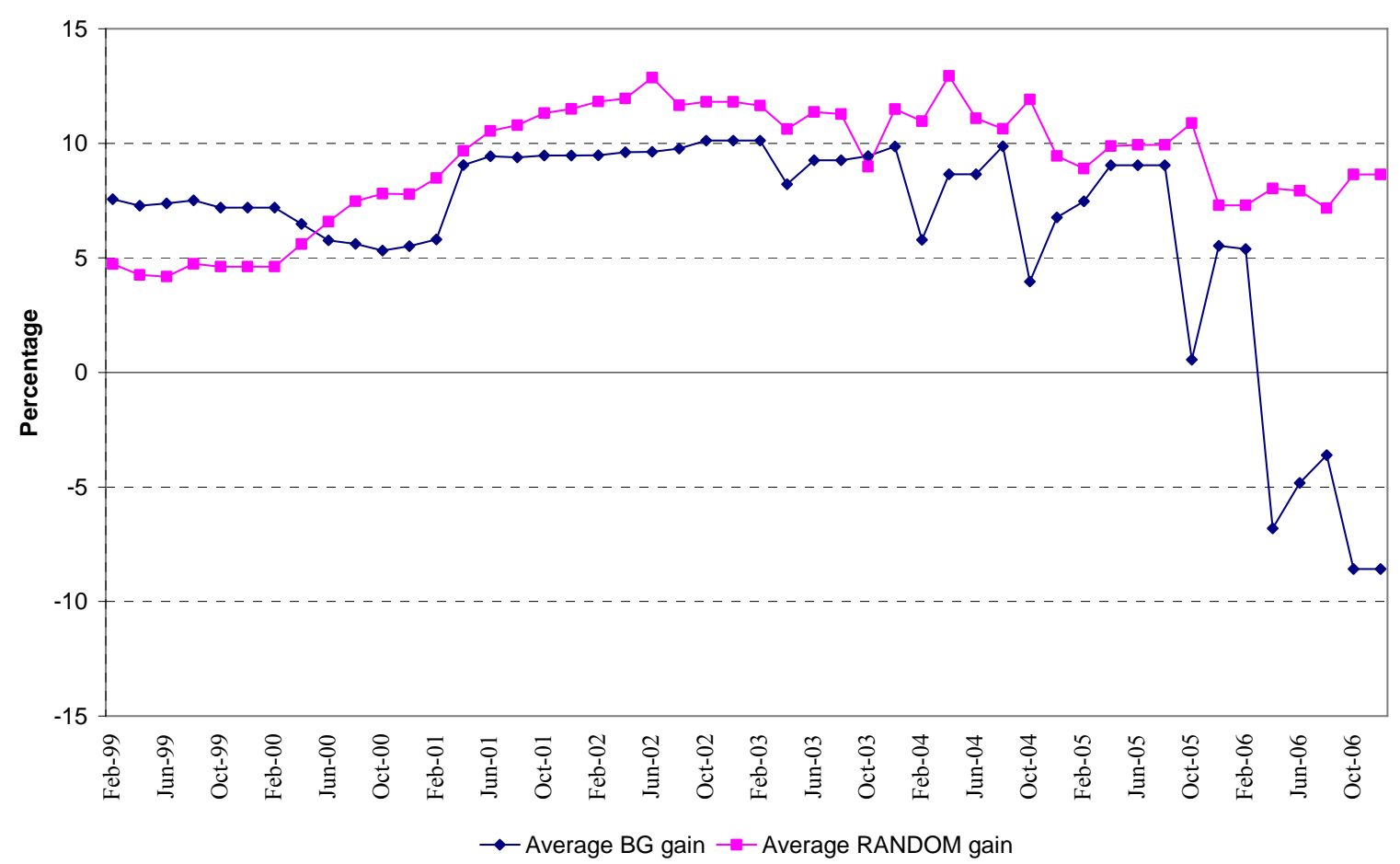

Figure 4. Gain from switching - Direct Debit low users (1650 KWh)

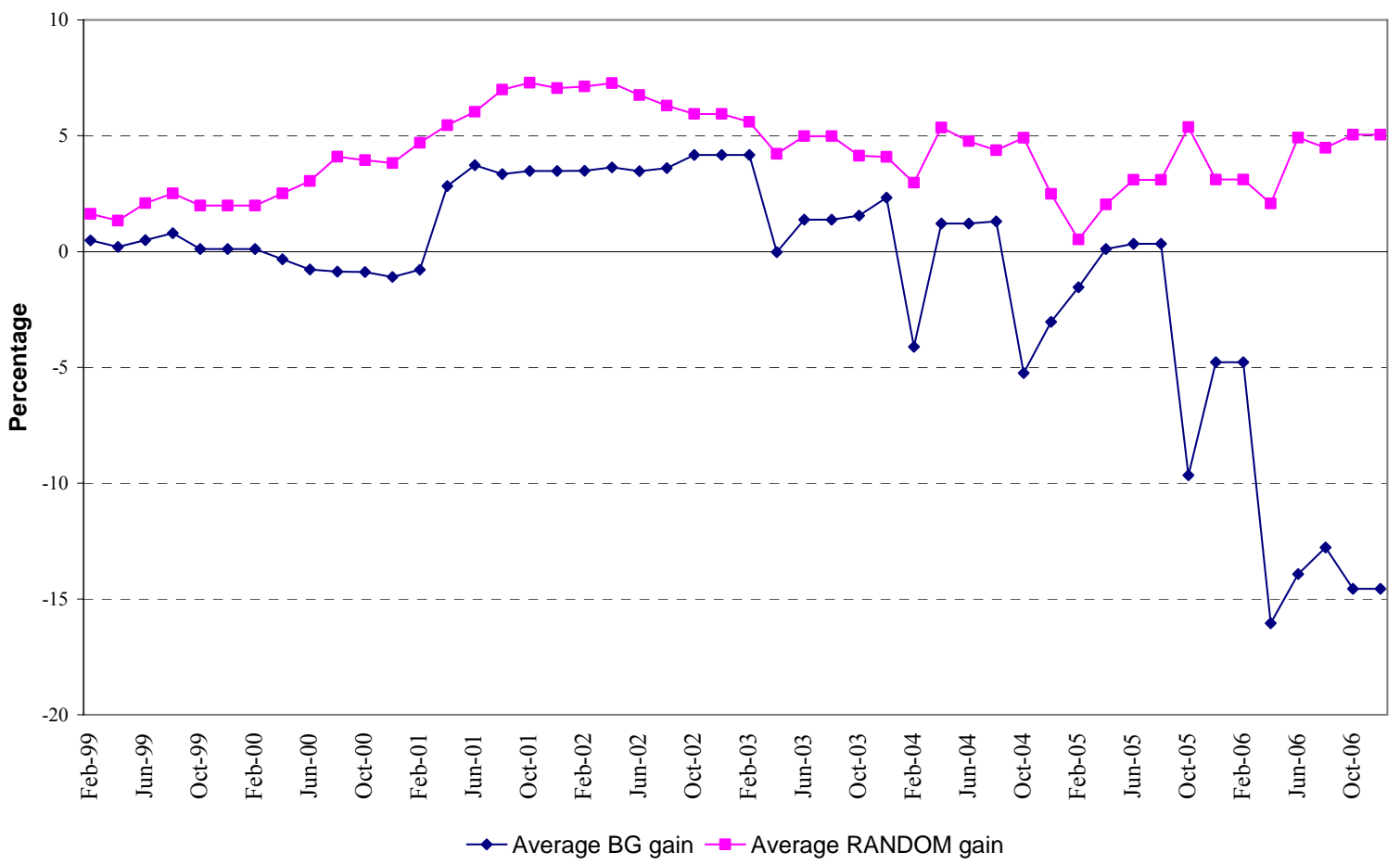


Figure 5. Fuel input prices for electricity producers

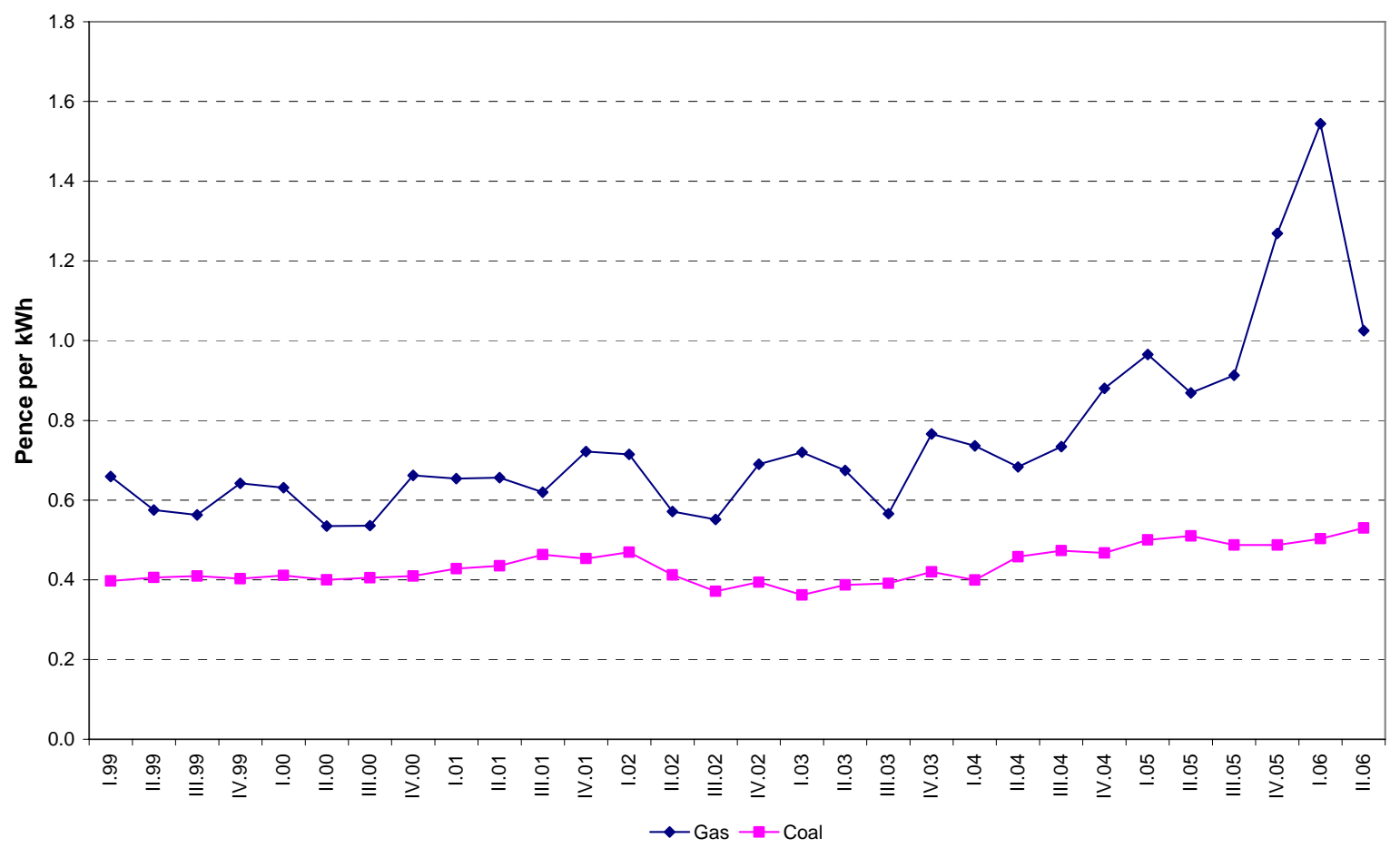

Source: UK Department of Trade and Industry. Quarterly Energy Prices Tables - December 2006 (Table 3.2.1). 
Table 1 - The bootstrap $Z_{\tau}$ Hadri test

\begin{tabular}{|c|c|c|c|c|c|}
\hline \multirow[t]{2}{*}{ Series } & \multirow[t]{2}{*}{ Block size } & \multicolumn{2}{|c|}{ Feb. 1999 - Apr. 2002} & \multicolumn{2}{|c|}{ Jun. 2002 - Dec. 2006} \\
\hline & & Test stat. & $p$-value & Test stat. & $p$-value \\
\hline \multirow{3}{*}{ ML } & 4 & \multirow{3}{*}{10.27} & 0.53 & \multirow{3}{*}{11.16} & 0.48 \\
\hline & 6 & & 0.53 & & 0.47 \\
\hline & 8 & & 0.46 & & 0.41 \\
\hline \multirow{3}{*}{$\mathrm{HL}$} & 4 & \multirow{3}{*}{10.78} & 0.45 & \multirow{3}{*}{11.28} & 0.41 \\
\hline & 6 & & 0.45 & & 0.43 \\
\hline & 8 & & 0.41 & & 0.40 \\
\hline \multirow{3}{*}{ IM } & 4 & \multirow{3}{*}{9.12} & 0.77 & \multirow{3}{*}{10.89} & 0.48 \\
\hline & 6 & & 0.71 & & 0.48 \\
\hline & 8 & & 0.62 & & 0.43 \\
\hline \multirow{3}{*}{ IB } & 4 & \multirow{3}{*}{7.57} & 0.87 & \multirow{3}{*}{11.94} & 0.33 \\
\hline & 6 & & 0.83 & & 0.33 \\
\hline & 8 & & 0.74 & & 0.34 \\
\hline
\end{tabular}

Notes: We first calculate individual KPSS test statistics using a lag truncation parameter equal to six, which accounts for potential residual serial correlation in the series. The average of the individual KPSS statistics is subsequently standardised, using mean and variance given by Hadri (2000), to obtain the Hadri test statistic. To do the block bootstrap, we regress $Y_{r p c, t}$ on a constant and a trend for the $Z_{\tau}$ test. Then, overlapping blocks of residuals (of size 4, 6 and 8) from these regressions are resampled keeping the cross-section index fixed, so that the cross-correlation structure of the error term is preserved. The $p$-values reported in the table are based upon 1,000 bootstrap replications. 
Table 2 - Unrestricted model. Tests of hypotheses

\begin{tabular}{|c|c|c|c|c|c|c|c|c|}
\hline & \multicolumn{8}{|c|}{ Dependent variable } \\
\hline & \multicolumn{2}{|c|}{$\Delta \mathrm{ML}$} & \multicolumn{2}{|c|}{$\Delta \mathrm{HL}$} & \multicolumn{2}{|c|}{$\Delta \mathrm{IM}$} & \multicolumn{2}{|c|}{$\Delta \mathrm{IB}$} \\
\hline \multicolumn{9}{|l|}{ Feb. 1999 - Apr. 2002} \\
\hline 1. DD High (Group 1) & 3.09 & {$[0.00]$} & 0.35 & {$[0.98]$} & 0.67 & {$[0.80]$} & 2.09 & [0.01] \\
\hline 2. PP High (Group 2) & 2.46 & {$[0.00]$} & 1.32 & {$[0.20]$} & 3.73 & {$[0.00]$} & 3.32 & {$[0.00]$} \\
\hline 3. QB High (Group 3) & 2.24 & {$[0.01]$} & 0.58 & {$[0.87]$} & 0.80 & {$[0.66]$} & 2.76 & {$[0.00]$} \\
\hline 4. DD Low (Group 4) & 0.43 & {$[0.96]$} & 0.10 & {$[1.00]$} & 1.18 & {$[0.29]$} & 1.18 & {$[0.28]$} \\
\hline 5. PP Low (Group 5) & 1.29 & {$[0.21]$} & 0.81 & {$[0.65]$} & 0.52 & [0.91] & 0.12 & [1.00] \\
\hline 6. QB Low (Group 6) & 0.49 & {$[0.93]$} & 0.35 & {$[0.98]$} & 0.97 & {$[0.48]$} & 1.48 & {$[0.12]$} \\
\hline 7. DD High $=P P$ High $=$ QB High & 1.54 & {$[0.02]$} & 0.67 & {$[0.95]$} & 1.36 & {$[0.07]$} & 1.90 & {$[0.00]$} \\
\hline 8. $\mathrm{DD}$ Low $=\mathrm{PP}$ Low $=\mathrm{QB}$ Low & 0.66 & {$[0.95]$} & 0.92 & {$[0.61]$} & 0.79 & [0.82] & 0.89 & [0.67] \\
\hline 9. $\mathrm{DD}$ Low $=\mathrm{PP}$ Low $=\mathrm{QB}$ Low $=0$ & 0.73 & {$[0.90]$} & 0.95 & {$[0.57]$} & 0.78 & {$[0.84]$} & 0.96 & {$[0.54]$} \\
\hline \multicolumn{9}{|l|}{ Jun. 2002 - Dec. 2006} \\
\hline 10. DD High (Group 1) & 0.60 & {$[0.86]$} & 0.49 & {$[0.93]$} & 6.17 & [0.00] & 2.55 & [0.00] \\
\hline 11. PP High (Group 2) & 1.38 & {$[0.16]$} & 1.09 & {$[0.36]$} & 4.70 & {$[0.00]$} & 2.11 & [0.01] \\
\hline 12. QB High (Group 3) & 1.21 & {$[0.26]$} & 0.37 & {$[0.98]$} & 3.97 & {$[0.00]$} & 1.82 & [0.04] \\
\hline 13. DD Low (Group 4) & 0.79 & {$[0.68]$} & 0.44 & {$[0.96]$} & 2.19 & {$[0.01]$} & 1.15 & [0.31] \\
\hline 14. PP Low (Group 5) & 0.28 & [0.99] & 1.45 & {$[0.13]$} & 0.62 & {$[0.84]$} & 0.54 & [0.90] \\
\hline 15. QB Low (Group 6) & 1.20 & {$[0.27]$} & 0.64 & {$[0.82]$} & 1.12 & [0.34] & 0.61 & {$[0.85]$} \\
\hline 16. DD High $=$ PP High $=$ QB High & 1.63 & {$[0.01]$} & 1.21 & {$[0.17]$} & 3.50 & {$[0.00]$} & 2.65 & {$[0.00]$} \\
\hline 17. $\mathrm{DD}$ Low $=\mathrm{PP}$ Low $=\mathrm{QB}$ Low & 1.02 & {$[0.44]$} & 0.89 & {$[0.68]$} & 1.11 & {$[0.30]$} & 1.44 & [0.04] \\
\hline 18. $\mathrm{DD}$ Low $=\mathrm{PP}$ Low $=\mathrm{QB}$ Low $=0$ & 1.59 & {$[0.01]$} & 1.33 & {$[0.08]$} & 1.67 & {$[0.00]$} & 1.43 & [0.04] \\
\hline
\end{tabular}

Notes: The tests of hypotheses refer to Wald tests that test whether the estimated coefficients associated to the variables within a group (as defined in Appendix 1) are statistically the same. In lines 9 and 18, the hypotheses refer to whether the estimated coefficients in the relevant groups are all equal to zero. The tests are reported in their F-version, with probability values in parentheses. 
Table 3 - Restricted model. Trend interaction by region and product. Feb. 99-Apr. 02

\begin{tabular}{|c|c|c|c|c|c|c|c|c|}
\hline \multirow[t]{2}{*}{ Regressors } & \multicolumn{2}{|c|}{$\Delta \mathrm{Y}=\Delta \mathrm{ML}$} & \multicolumn{2}{|c|}{$\Delta \mathrm{Y}=\Delta \mathrm{HL}$} & \multicolumn{2}{|c|}{$\Delta \mathrm{Y}=\Delta \mathrm{IM}$} & \multicolumn{2}{|c|}{$\Delta \mathrm{Y}=\Delta \mathrm{IB}$} \\
\hline & Coeff. & t-Stat & Coeff. & t-Stat & Coeff. & t-Stat & Coeff. & t-Stat \\
\hline $\mathrm{Y}(-1)$ & -0.27 & -9.16 & -0.16 & -6.04 & -0.07 & -2.65 & -0.07 & -4.44 \\
\hline NFIRMS & 0.09 & 1.54 & 0.34 & 3.22 & 0.13 & 3.46 & 0.49 & 10.34 \\
\hline Group 1 & & & & & & & & \\
\hline$\overline{\mathrm{Tr}^{*} \mathrm{EA} * \mathrm{DD}}$ & -0.11 & -3.53 & -0.21 & -3.70 & 0.05 & 1.87 & 0.16 & 7.29 \\
\hline Tr*EM*DD & -0.09 & -2.19 & -0.19 & -2.83 & 0.04 & 1.45 & 0.15 & 7.22 \\
\hline Tr*LD*DD & -0.05 & -1.57 & -0.19 & -3.31 & 0.05 & 2.25 & 0.18 & 7.69 \\
\hline $\mathrm{Tr}^{*} \mathrm{MD} * \mathrm{DD}$ & -0.07 & -2.25 & -0.19 & -3.56 & 0.03 & 1.33 & 0.16 & 7.07 \\
\hline $\mathrm{Tr}^{*} \mathrm{MW}{ }^{*} \mathrm{DD}$ & -0.09 & -2.65 & -0.20 & -3.54 & 0.05 & 1.50 & 0.17 & 6.44 \\
\hline $\mathrm{Tr}^{*} \mathrm{NT} * \mathrm{DD}$ & -0.01 & -0.37 & -0.10 & -1.67 & 0.07 & 2.23 & 0.17 & 7.55 \\
\hline $\mathrm{Tr}^{*} \mathrm{NW} \mathrm{W}^{*} \mathrm{DD}$ & -0.10 & -2.87 & -0.21 & -3.93 & 0.06 & 2.03 & 0.16 & 7.33 \\
\hline Tr*SE*DD & -0.07 & -1.70 & -0.19 & -3.26 & 0.05 & 1.43 & 0.16 & 5.08 \\
\hline $\mathrm{Tr}^{*} \mathrm{SH}{ }^{*} \mathrm{DD}$ & -0.04 & -1.14 & -0.16 & -3.29 & 0.07 & 2.37 & 0.24 & 9.09 \\
\hline $\mathrm{Tr} * \mathrm{SP} * \mathrm{DD}$ & -0.10 & -3.91 & -0.17 & -3.55 & 0.07 & 1.89 & 0.22 & 7.95 \\
\hline $\mathrm{Tr}^{*} \mathrm{ST} * \mathrm{DD}$ & -0.08 & -3.02 & -0.21 & -4.11 & 0.08 & 2.93 & 0.18 & 7.97 \\
\hline $\operatorname{Tr} * \mathrm{SA} * \mathrm{DD}$ & -0.05 & -1.60 & -0.20 & -3.92 & 0.05 & 1.65 & 0.16 & 5.99 \\
\hline $\mathrm{Tr}^{*} \mathrm{SW} \mathrm{W}^{*} \mathrm{DD}$ & -0.11 & -4.34 & -0.20 & -4.29 & 0.04 & 1.54 & 0.17 & 6.13 \\
\hline Tr*YK*DD & -0.05 & -1.61 & -0.15 & -2.56 & 0.07 & 2.40 & 0.16 & 7.95 \\
\hline Group 2 & & & & & & & & \\
\hline Tr*EA*PP & -0.02 & -0.66 & 0.09 & 1.34 & 0.02 & 0.80 & 0.20 & 8.12 \\
\hline Tr*EM*PP & -0.01 & -0.12 & 0.10 & 1.00 & -0.01 & -0.51 & 0.17 & 6.54 \\
\hline Tr*LD*PP & -0.02 & -0.57 & 0.00 & -0.04 & 0.01 & 0.46 & 0.20 & 8.28 \\
\hline Tr*MD*PP & -0.03 & -1.02 & 0.01 & 0.13 & 0.01 & 0.31 & 0.19 & 8.40 \\
\hline Tr*MW*PP & 0.03 & 0.95 & -0.06 & -1.15 & 0.00 & 0.18 & 0.22 & 6.49 \\
\hline $\mathrm{Tr}^{*} \mathrm{NT} * \mathrm{PP}$ & 0.03 & 0.89 & -0.06 & -1.05 & 0.02 & 0.98 & 0.21 & 8.27 \\
\hline $\mathrm{Tr}^{*} \mathrm{NW} * \mathrm{PP}$ & 0.03 & 0.86 & 0.05 & 0.53 & 0.01 & 0.59 & 0.21 & 8.28 \\
\hline Tr*SE*PP & 0.05 & 1.26 & 0.08 & 1.13 & 0.05 & 1.40 & 0.19 & 8.30 \\
\hline Tr*SH*PP & -0.08 & -3.19 & -0.05 & -0.51 & 0.06 & 2.46 & 0.27 & 9.87 \\
\hline Tr*SP*PP & -0.06 & -2.16 & -0.09 & -1.66 & 0.03 & 1.29 & 0.23 & 8.39 \\
\hline Tr*ST*PP & -0.01 & -0.17 & -0.05 & -0.68 & 0.06 & 2.45 & 0.23 & 8.97 \\
\hline Tr*SA*PP & -0.01 & -0.41 & -0.08 & -1.40 & 0.02 & 1.09 & 0.22 & 8.92 \\
\hline Tr*SW*PP & -0.01 & -0.29 & -0.05 & -0.80 & 0.02 & 0.77 & 0.19 & 8.20 \\
\hline Tr*YK*PP & 0.04 & 1.14 & -0.02 & -0.31 & 0.00 & -0.01 & 0.19 & 7.57 \\
\hline Group 3 & & & & & & & & \\
\hline$\overline{\operatorname{Tr}^{*} \mathrm{EA}^{*} \mathrm{QB}}$ & -0.11 & -2.99 & -0.20 & -3.52 & 0.04 & 1.50 & 0.17 & 7.06 \\
\hline Tr*EM*QB & -0.07 & -1.93 & -0.16 & -2.54 & 0.02 & 1.07 & 0.15 & 7.22 \\
\hline Tr*LD*QB & -0.06 & -1.99 & -0.15 & -3.02 & 0.03 & 1.32 & 0.17 & 7.74 \\
\hline $\mathrm{Tr}^{*} \mathrm{MD}{ }^{*} \mathrm{QB}$ & -0.05 & -1.63 & -0.14 & -2.62 & 0.00 & 0.22 & 0.15 & 6.89 \\
\hline $\mathrm{Tr}^{*} \mathrm{MW}^{*} \mathrm{QB}$ & -0.08 & -2.67 & -0.19 & -3.44 & 0.03 & 1.33 & 0.17 & 7.66 \\
\hline $\mathrm{Tr}^{*} \mathrm{NT} * \mathrm{QB}$ & 0.00 & 0.11 & -0.09 & -1.46 & 0.06 & 2.16 & 0.18 & 8.06 \\
\hline $\mathrm{Tr}^{*} \mathrm{NW}^{*} \mathrm{QB}$ & -0.08 & -2.42 & -0.20 & -4.05 & 0.04 & 1.85 & 0.16 & 7.19 \\
\hline $\mathrm{Tr} * \mathrm{SE} * \mathrm{QB}$ & -0.06 & -1.63 & -0.17 & -3.21 & 0.03 & 1.09 & 0.15 & 7.01 \\
\hline Tr*SH*QB & -0.07 & -2.24 & -0.17 & -3.58 & 0.06 & 2.28 & 0.24 & 8.98 \\
\hline $\mathrm{Tr}^{*} \mathrm{SP} * \mathrm{QB}$ & -0.11 & -3.60 & -0.19 & -3.95 & 0.05 & 1.71 & 0.22 & 8.74 \\
\hline Tr*ST*QB & -0.08 & -2.38 & -0.17 & -3.37 & 0.07 & 2.71 & 0.19 & 8.06 \\
\hline $\mathrm{Tr}^{*} \mathrm{SA} * \mathrm{QB}$ & -0.05 & -1.57 & -0.17 & -3.59 & 0.04 & 1.49 & 0.17 & 7.52 \\
\hline $\mathrm{Tr} * \mathrm{SW} * \mathrm{QB}$ & -0.09 & -3.25 & -0.18 & -4.10 & 0.03 & 1.27 & 0.17 & 7.46 \\
\hline $\mathrm{Tr}^{*} \mathrm{YK}^{*} \mathrm{QB}$ & -0.03 & -0.89 & -0.14 & -2.61 & 0.04 & 1.49 & 0.16 & 8.11 \\
\hline R-squared & 0.16 & & 0.13 & & 0.14 & & 0.25 & \\
\hline Adjusted R-squared & 0.13 & & 0.10 & & 0.12 & & 0.23 & \\
\hline S.E. of regression & 2.69 & & 5.42 & & 1.86 & & 1.86 & \\
\hline F-statistic [ $p$-value $]$ & 5.57 & {$[0.00]$} & 4.42 & {$[0.00]$} & 5.05 & {$[0.00]$} & 10.11 & {$[0.00]$} \\
\hline Tests of hypotheses & & & & & & & & \\
\hline Group 1 & 1.29 & {$[0.21]$} & 0.40 & [0.97] & 0.80 & {$[0.66]$} & 2.61 & {$[0.00]$} \\
\hline Group 2 & 2.21 & {$[0.01]$} & 1.45 & {$[0.13]$} & 3.24 & {$[0.00]$} & 4.77 & {$[0.00]$} \\
\hline Group 3 & 1.02 & {$[0.43]$} & 0.39 & [0.97] & 1.44 & [0.13] & 3.39 & {$[0.00]$} \\
\hline
\end{tabular}

Notes: The tests of hypotheses refer to Wald tests that test whether the estimated coefficients associated to the variables within a group are statistically the same. The tests are reported in their F-version, with probability values in parentheses. The variables are defined in the notes in Appendix 1. 
Table 4 - Restricted model. Trend interaction by region and product. Jun. 02-Dec. 06

\begin{tabular}{|c|c|c|c|c|c|c|c|c|}
\hline \multirow[t]{2}{*}{ Regressors } & \multicolumn{2}{|c|}{$\Delta \mathrm{Y}=\Delta \mathrm{ML}$} & \multicolumn{2}{|c|}{$\Delta \mathrm{Y}=\Delta \mathrm{HL}$} & \multicolumn{2}{|c|}{$\Delta \mathrm{Y}=\Delta \mathrm{IM}$} & \multicolumn{2}{|c|}{$\Delta \mathrm{Y}=\Delta \mathrm{IB}$} \\
\hline & Coeff. & $\mathrm{t}-\mathrm{Stat}$ & Coeff. & t-Stat & Coeff. & t-Stat & Coeff. & t-Stat \\
\hline $\mathrm{Y}(-1)$ & -0.40 & -10.30 & -0.16 & -7.09 & -0.13 & -6.34 & -0.11 & -5.63 \\
\hline NFIRMS & 0.64 & 7.03 & 1.17 & 8.04 & -0.34 & -2.90 & -1.12 & -8.83 \\
\hline Group 1 & & & & & & & & \\
\hline$\overline{\mathrm{Tr}^{*} \mathrm{EA} * \mathrm{DD}}$ & 0.09 & 4.27 & 0.33 & 8.47 & -0.03 & -1.11 & -0.28 & -9.69 \\
\hline Tr*EM*DD & 0.10 & 4.77 & 0.34 & 8.32 & -0.03 & -1.32 & -0.28 & -9.89 \\
\hline Tr*LD*DD & 0.11 & 5.15 & 0.32 & 8.02 & -0.06 & -2.37 & -0.31 & -9.70 \\
\hline $\mathrm{Tr}^{*} \mathrm{MD} * \mathrm{DD}$ & 0.08 & 4.06 & 0.32 & 8.04 & -0.03 & -1.36 & -0.28 & -9.42 \\
\hline $\mathrm{Tr}^{*} \mathrm{MW}{ }^{*} \mathrm{DD}$ & 0.08 & 3.85 & 0.30 & 7.88 & -0.07 & -3.20 & -0.31 & -9.81 \\
\hline Tr*NT*DD & 0.09 & 4.53 & 0.33 & 8.17 & -0.02 & -0.73 & -0.28 & -9.46 \\
\hline $\mathrm{Tr}^{*} \mathrm{NW} \mathrm{W}^{*} \mathrm{DD}$ & 0.09 & 4.36 & 0.36 & 6.79 & -0.02 & -0.76 & -0.28 & -9.62 \\
\hline Tr*SE*DD & 0.10 & 4.73 & 0.33 & 8.07 & -0.05 & -2.15 & -0.31 & -9.57 \\
\hline $\mathrm{Tr}^{*} \mathrm{SH}{ }^{*} \mathrm{DD}$ & 0.09 & 4.04 & 0.31 & 8.26 & -0.10 & -3.76 & -0.36 & -9.99 \\
\hline $\mathrm{Tr} * \mathrm{SP} * \mathrm{DD}$ & 0.12 & 4.79 & 0.32 & 7.97 & -0.08 & -3.51 & -0.33 & -10.22 \\
\hline $\mathrm{Tr}^{*} \mathrm{ST} * \mathrm{DD}$ & 0.12 & 5.07 & 0.35 & 8.73 & -0.08 & -3.08 & -0.33 & -9.17 \\
\hline $\operatorname{Tr} * \mathrm{SA} * \mathrm{DD}$ & 0.09 & 4.19 & 0.33 & 8.26 & -0.09 & -3.82 & -0.36 & -9.52 \\
\hline $\mathrm{Tr}^{*} \mathrm{SW} \mathrm{W}^{*} \mathrm{DD}$ & 0.10 & 5.20 & 0.33 & 8.71 & -0.05 & -2.13 & -0.31 & -8.60 \\
\hline Tr*YK*DD & 0.09 & 4.28 & 0.34 & 8.76 & -0.03 & -1.29 & -0.29 & -9.35 \\
\hline Group 2 & & & & & & & & \\
\hline Tr*EA*PP & 0.13 & 5.72 & 0.35 & 7.56 & -0.07 & -2.43 & -0.32 & -9.59 \\
\hline Tr*EM*PP & 0.16 & 5.86 & 0.38 & 9.00 & -0.07 & -2.25 & -0.32 & -9.60 \\
\hline Tr*LD*PP & 0.14 & 5.37 & 0.34 & 6.42 & -0.09 & -3.37 & -0.36 & -9.72 \\
\hline Tr*MD*PP & 0.13 & 6.09 & 0.33 & 7.27 & -0.03 & -1.20 & -0.30 & -9.20 \\
\hline Tr*MW*PP & 0.12 & 5.73 & 0.39 & 9.03 & -0.07 & -2.73 & -0.34 & -9.69 \\
\hline $\mathrm{Tr}^{*} \mathrm{NT} * \mathrm{PP}$ & 0.15 & 6.91 & 0.37 & 7.92 & -0.02 & -0.91 & -0.30 & -9.48 \\
\hline Tr*NW*PP & 0.17 & 6.81 & 0.37 & 7.47 & -0.07 & -2.56 & -0.32 & -9.67 \\
\hline Tr*SE*PP & 0.12 & 4.69 & 0.34 & 6.37 & -0.08 & -3.11 & -0.34 & -9.81 \\
\hline Tr*SH*PP & 0.10 & 4.36 & 0.35 & 8.39 & -0.11 & -3.71 & -0.39 & -9.52 \\
\hline Tr*SP*PP & 0.14 & 5.36 & 0.42 & 9.19 & -0.07 & -2.62 & -0.38 & -10.05 \\
\hline Tr*ST*PP & 0.13 & 4.82 & 0.37 & 6.91 & -0.07 & -2.52 & -0.35 & -9.03 \\
\hline Tr*SA*PP & 0.13 & 5.43 & 0.38 & 9.12 & -0.09 & -3.41 & -0.37 & -9.27 \\
\hline Tr*SW*PP & 0.14 & 5.43 & 0.36 & 7.51 & -0.09 & -3.41 & -0.36 & -9.78 \\
\hline Tr*YK*PP & 0.15 & 5.81 & 0.36 & 8.33 & -0.02 & -0.95 & -0.31 & -9.40 \\
\hline Group 3 & & & & & & & & \\
\hline$\overline{\operatorname{Tr}^{*} \mathrm{EA}^{*} \mathrm{QB}}$ & 0.13 & 5.28 & 0.35 & 8.40 & -0.06 & -2.13 & -0.31 & -9.76 \\
\hline $\operatorname{Tr}^{*} \mathrm{EM}^{*} \mathrm{QB}$ & 0.13 & 5.34 & 0.35 & 8.73 & -0.06 & -2.14 & -0.31 & -9.87 \\
\hline Tr*LD*QB & 0.15 & 5.78 & 0.34 & 7.87 & -0.09 & -3.35 & -0.34 & -9.96 \\
\hline $\mathrm{Tr}^{*} \mathrm{MD}{ }^{*} \mathrm{QB}$ & 0.13 & 5.64 & 0.34 & 8.47 & -0.05 & -2.17 & -0.30 & -9.23 \\
\hline $\mathrm{Tr}^{*} \mathrm{MW}^{*} \mathrm{QB}$ & 0.10 & 4.25 & 0.32 & 8.27 & -0.07 & -2.64 & -0.32 & -9.43 \\
\hline $\mathrm{Tr}^{*} \mathrm{NT} * \mathrm{QB}$ & 0.14 & 6.10 & 0.34 & 8.41 & -0.05 & -1.93 & -0.30 & -9.23 \\
\hline $\mathrm{Tr}^{*} \mathrm{NW}^{*} \mathrm{QB}$ & 0.11 & 4.82 & 0.37 & 7.48 & -0.05 & -1.89 & -0.32 & -9.82 \\
\hline $\mathrm{Tr} * \mathrm{SE} * \mathrm{QB}$ & 0.15 & 5.94 & 0.35 & 7.61 & -0.09 & -3.28 & -0.34 & -9.46 \\
\hline Tr*SH*QB & 0.11 & 4.41 & 0.32 & 8.35 & -0.11 & -4.05 & -0.39 & -10.02 \\
\hline $\mathrm{Tr}^{*} \mathrm{SP} * \mathrm{QB}$ & 0.12 & 4.53 & 0.35 & 8.38 & -0.07 & -2.66 & -0.34 & -9.70 \\
\hline Tr*ST*QB & 0.11 & 4.94 & 0.33 & 8.03 & -0.10 & -3.66 & -0.36 & -9.43 \\
\hline $\mathrm{Tr}^{*} \mathrm{SA} * \mathrm{QB}$ & 0.10 & 4.58 & 0.32 & 8.61 & -0.11 & -4.33 & -0.38 & -9.79 \\
\hline $\mathrm{Tr} * \mathrm{SW} * \mathrm{QB}$ & 0.12 & 4.71 & 0.34 & 8.46 & -0.08 & -3.46 & -0.34 & -9.82 \\
\hline $\mathrm{Tr}^{*} \mathrm{YK}^{*} \mathrm{QB}$ & 0.15 & 6.48 & 0.35 & 8.76 & -0.05 & -2.17 & -0.31 & -9.03 \\
\hline R-squared & 0.26 & & 0.20 & & 0.21 & & 0.28 & \\
\hline Adjusted R-squared & 0.24 & & 0.18 & & 0.19 & & 0.26 & \\
\hline S.E. of regression & 3.29 & & 6.23 & & 3.47 & & 4.38 & \\
\hline F-statistic [ $p$-value $]$ & 13.78 & {$[0.00]$} & 10.14 & {$[0.00]$} & 10.40 & {$[0.00]$} & 15.38 & {$[0.00]$} \\
\hline Tests of hypotheses & & & & & & & & \\
\hline Group 1 & 0.85 & {$[0.61]$} & 0.36 & {$[0.98]$} & 3.37 & {$[0.00]$} & 2.02 & {$[0.02]$} \\
\hline Group 2 & 1.55 & {$[0.09]$} & 1.01 & {$[0.44]$} & 3.52 & {$[0.00]$} & 2.20 & {$[0.01]$} \\
\hline Group 3 & 1.40 & {$[0.15]$} & 0.41 & [0.97] & 2.38 & {$[0.00]$} & 1.76 & {$[0.04]$} \\
\hline
\end{tabular}

Notes: The tests of hypotheses refer to Wald tests that test whether the estimated coefficients associated to the variables within a group are statistically the same. The tests are reported in their F-version, with probability values in parentheses. The variables are defined in the notes in Appendix 1. 


\section{References}

Battisti, G, Giulietti, M., Basioudis, D., 2006. Switching as a diffusion process: Evidence from the UK residential gas market. Aston Business School Research Paper 0623 (July). Aston University, United Kingdom.

Baye, M., Morgan, J., 2001. Information gatekeepers on the internet and the competitiveness of homogeneous product markets. American Economic Review 91, 454-474.

Baye, M., Morgan, J., Scholten, P., 2004. Price dispersion in the small and in the large: evidence from an internet price comparison site. Journal of Industrial Economics 52, 463-496.

Berkowitz, J., Kilian, L., 2000. Recent developments in bootstrapping time series. Econometric Reviews 19, 1-48.

Brown, J., Goolsbee, A., 2002. Does the internet make markets more competitive: Evidence from the life insurance industry. Journal of Political Economy 110, 481-507.

Burdett, K., Judd, K.L., 1983. Equilibrium price dispersion. Econometrica 51, 955-970.

Chang, Y., 2004. Bootstrap unit root tests in panels with cross-sectional dependency. Journal of Econometrics 120, 263-293.

Cecchetti, S., Nelson, M., Sonora, R., 2002. Price level convergence among United States cities: Lessons for the European Central Bank. International Economic Review 43, 10811099.

Ellison, G., Ellison, S.F., 2005. Lessons about markets from the Internet. Journal of Economic Perspectives 19, 139-158.

Frankel, J.A., Rose, A., 1996. A panel project on purchasing power parity: Mean reversion within and between countries. Journal of International Economics 40, 209-224. 
Giulietti, M., Otero, J., Smith, J., 2006. Testing for stationarity in heterogeneous panel data in the presence of cross section dependence. Warwick Economics Research Papers Series 758, Warwick University, United Kingdom.

Giulietti, M., Waddams Price, C., Waterson, M., 2005. Consumer choice and competition policy: A study of UK energy markets. The Economic Journal 115, 949-968.

Goldberg, P., Verboven, F., 2005. Market integration and convergence to the law of one price: Evidence from the European car market. Journal of International Economics 65, 49-73.

Green, R., 2005. Dual fuel competition in British energy retail markets. Mimeo, University of Hull.

Hadri, K., 2000. Testing for stationarity in heterogeneous panel data. The Econometrics Journal 3, 148-161.

Hong, H., Shum, M., 2006. Using price distributions to estimate search costs. The Rand Journal of Economics 37, 257-275.

Im, K., Pesaran, M.H., Shin, Y., 2003. Testing for unit roots in heterogeneous panel. Journal of Econometrics 115, 53-74.

Janssen, M., Moraga-Gonzalez, J., 2004. Strategic pricing and the number of firms. Review of Economic Studies 71, 1089-1118.

Judson, R.A., Owen, A.L., 1999. Estimating dynamic panel data models: a guide for macroeconomists. Economics Letters 65, 9-15.

Künsch, H.R., 1989. The jackknife and the bootstrap for general stationary observations. Annals of Statistics 17, 1217-1241.

Kwiatkowski, D., Phillips, P.C.B., Schmidt, P., Shin, Y., 1992. Testing the null hypothesis of stationarity against the alternative of a unit root. Journal of Econometrics 54, 159-178. 
Lee, H.-Y., Wu, L.-J., 2001. Mean reversion of inflation rates: Evidence from 13 OECD countries. Journal of Macroeconomics 23, 477-487.

Maddala, G. S., Kim, I.M., 1998. Unit Roots, Cointegration, and Structural Change. Cambridge University Press, Cambridge.

Maddala, G.S., Wu S., 1999. A comparative study of unit root tests with panel data and a new simple test. Oxford Bulletin of Economics and Statistics 61, 631-652.

Moraga-González, J.L., Wildenbeest, M.R., 2006. Maximum likelihood estimation of search costs. Tinbergen Institute Discussion Paper TI 2006-019/1.

Morgan, J., Orzen, H., Sefton, M., 2006. An experimental study of price dispersion. Games and Economic Behavior 54, 131-158.

OFGEM, 2003. Domestic Gas and Electricity Supply Competition: Recent Developments. June.

OFGEM, 2004. Domestic competitive market review, March.

Pesaran, M.H., 2007. A simple panel unit root test in the presence of cross section dependence. Journal of Applied Econometrics, forthcoming.

Stahl, D., 1989. Oligopolistic pricing with sequential consumer search.American Economic Review 79, 700-712.

Strauss, J., Yigit, T., 2003. Shortfalls of panel unit root testing. Economics Letters 81, 309313.

Varian, H., 1980. A model of sales. American Economic Review 70, 651-659. 
Appendix 1. Unrestricted model. Trend interaction by region, products and consumption levels

\begin{tabular}{|c|c|c|c|c|c|c|c|c|c|c|c|c|c|c|c|c|}
\hline \multirow[t]{3}{*}{ Regressors } & \multicolumn{4}{|c|}{$\Delta \mathrm{Y}=\Delta \mathrm{ML}$} & \multicolumn{4}{|c|}{$\Delta \mathrm{Y}=\Delta \mathrm{HL}$} & \multicolumn{4}{|c|}{$\Delta \mathrm{Y}=\Delta \mathrm{IM}$} & \multicolumn{4}{|c|}{$\Delta \mathrm{Y}=\Delta \mathrm{IB}$} \\
\hline & \multicolumn{2}{|c|}{ Feb. 99-Apr. 02} & \multicolumn{2}{|c|}{ Jun. 02-Dec. 06} & \multicolumn{2}{|c|}{ Feb. 99-Apr. 02} & \multicolumn{2}{|c|}{ Jun. 02-Dec. 06} & \multicolumn{2}{|c|}{ Feb. 99-Apr. 02} & \multicolumn{2}{|c|}{ Jun. 02-Dec. 06} & \multicolumn{2}{|c|}{ Feb. 99-Apr. 02} & \multicolumn{2}{|c|}{ Jun. 02-Dec. 06} \\
\hline & Coeff. & t-Stat & Coeff. & $\mathrm{t}-\mathrm{Stat}$ & Coeff. & t-Stat & Coeff. & t-Stat & Coeff. & t-Stat & Coeff. & t-Stat & Coeff. & t-Stat & Coeff. & t-Stat \\
\hline $\mathrm{Y}(-1)$ & -0.33 & -8.63 & -0.52 & -12.30 & -0.18 & -6.29 & -0.25 & -7.06 & -0.20 & -3.69 & -0.31 & -9.94 & -0.20 & -5.60 & -0.34 & -8.24 \\
\hline NFIRMS & 0.10 & 1.69 & 0.66 & 7.06 & 0.35 & 3.19 & 1.19 & 8.05 & 0.09 & 2.55 & -0.27 & -2.38 & 0.38 & 7.07 & -1.23 & -9.45 \\
\hline \multicolumn{17}{|l|}{ Group 1} \\
\hline Tr*EA*DD & -0.13 & -4.76 & 0.08 & 3.61 & -0.19 & -3.12 & 0.34 & 8.16 & 0.15 & 3.44 & -0.01 & -0.20 & 0.19 & 7.45 & -0.37 & -11.04 \\
\hline Tr*EM*DD & -0.09 & -2.30 & 0.08 & 3.45 & -0.17 & -2.28 & 0.31 & 7.33 & 0.13 & 3.35 & 0.00 & -0.06 & 0.22 & 8.31 & -0.35 & -11.02 \\
\hline Tr*LD*DD & -0.06 & -1.95 & 0.10 & 4.24 & -0.19 & -2.74 & 0.32 & 6.94 & 0.12 & 3.68 & -0.03 & -0.96 & 0.22 & 8.89 & -0.37 & -9.89 \\
\hline $\mathrm{Tr}^{*} \mathrm{MD} * \mathrm{DD}$ & -0.10 & -3.46 & 0.08 & 3.50 & -0.20 & -3.32 & 0.32 & 7.72 & 0.16 & 3.45 & 0.03 & 1.44 & 0.23 & 8.90 & -0.32 & -9.33 \\
\hline $\mathrm{Tr}^{*} \mathrm{MW}{ }^{*} \mathrm{DD}$ & -0.10 & -3.26 & 0.10 & 3.49 & -0.19 & -2.83 & 0.31 & 7.25 & 0.15 & 3.01 & -0.05 & -2.13 & 0.24 & 7.19 & -0.38 & -9.64 \\
\hline Tr*NT*DD & -0.03 & -1.19 & 0.08 & 3.62 & -0.13 & -1.80 & 0.38 & 7.59 & 0.19 & 3.54 & 0.07 & 2.40 & 0.21 & 8.37 & -0.33 & -9.51 \\
\hline $\mathrm{Tr}^{*} \mathrm{NW} \mathrm{WDD}^{*}$ & -0.12 & -4.28 & 0.08 & 3.39 & -0.24 & -4.13 & 0.35 & 5.00 & 0.16 & 3.42 & 0.01 & 0.52 & 0.22 & 8.27 & -0.35 & -11.14 \\
\hline Tr*SE*DD & -0.12 & -3.54 & 0.09 & 4.13 & -0.20 & -3.21 & 0.33 & 7.03 & 0.17 & 3.62 & -0.01 & -0.44 & 0.19 & 6.65 & -0.38 & -9.88 \\
\hline Tr*SH*DD & -0.01 & -0.46 & 0.09 & 3.02 & -0.16 & -3.64 & 0.29 & 7.21 & 0.12 & 2.98 & -0.12 & -3.90 & 0.32 & 8.82 & -0.44 & -9.69 \\
\hline Tr*SP*DD & -0.13 & -5.00 & 0.14 & 3.99 & -0.19 & -3.36 & 0.34 & 6.30 & 0.16 & 3.33 & -0.07 & -2.72 & 0.30 & 8.13 & -0.39 & -10.04 \\
\hline Tr*ST*DD & -0.12 & -4.87 & 0.13 & 4.54 & -0.22 & -3.48 & 0.35 & 7.79 & 0.16 & 3.89 & -0.07 & -2.46 & 0.23 & 8.09 & -0.42 & -9.13 \\
\hline Tr*SA*DD & -0.03 & -1.11 & 0.09 & 3.80 & -0.20 & -3.53 & 0.32 & 7.37 & 0.09 & 2.29 & -0.09 & -3.18 & 0.17 & 5.41 & -0.47 & -9.49 \\
\hline $\mathrm{Tr}^{*} \mathrm{SW} * \mathrm{DD}$ & -0.14 & -5.53 & 0.09 & 4.63 & -0.20 & -3.70 & 0.33 & 7.86 & 0.15 & 3.66 & -0.02 & -0.67 & 0.23 & 8.13 & -0.37 & -8.53 \\
\hline Tr*YK*DD & -0.06 & -1.86 & 0.08 & 3.50 & -0.14 & -2.27 & 0.35 & 8.02 & 0.18 & 3.72 & 0.05 & 1.65 & 0.21 & 8.77 & -0.33 & -9.23 \\
\hline \multicolumn{17}{|l|}{ Group 2} \\
\hline Tr*EA*PP & 0.02 & 0.41 & 0.13 & 5.17 & 0.08 & 0.91 & 0.36 & 6.91 & 0.00 & 0.17 & -0.07 & -2.81 & 0.19 & 7.06 & -0.46 & -11.13 \\
\hline Tr*EM*PP & 0.05 & 0.55 & 0.15 & 4.85 & 0.11 & 0.69 & 0.36 & 8.24 & -0.03 & -0.89 & -0.08 & -2.20 & 0.16 & 5.67 & -0.46 & -11.21 \\
\hline Tr*LD*PP & -0.01 & -0.12 & 0.15 & 5.22 & -0.01 & -0.12 & 0.37 & 6.60 & 0.00 & 0.04 & -0.10 & -3.26 & 0.19 & 7.58 & -0.50 & -10.58 \\
\hline Tr*MD*PP & 0.04 & 0.83 & 0.13 & 5.56 & 0.01 & 0.05 & 0.38 & 8.33 & 0.01 & 0.64 & 0.01 & 0.21 & 0.22 & 9.18 & -0.40 & -9.39 \\
\hline Tr*MW*PP & 0.06 & 1.21 & 0.12 & 5.51 & -0.11 & -1.81 & 0.39 & 8.14 & 0.01 & 0.26 & -0.06 & -2.22 & 0.24 & 5.66 & -0.45 & -9.59 \\
\hline Tr*NT*PP & 0.09 & 1.38 & 0.16 & 6.27 & -0.05 & -0.64 & 0.43 & 7.63 & 0.04 & 1.64 & 0.01 & 0.50 & 0.22 & 7.97 & -0.41 & -9.65 \\
\hline Tr*NW*PP & 0.05 & 1.11 & 0.17 & 5.50 & 0.08 & 0.62 & 0.40 & 6.73 & 0.02 & 0.71 & -0.06 & -2.17 & 0.20 & 7.47 & -0.46 & -11.16 \\
\hline Tr*SE*PP & 0.07 & 1.27 & 0.12 & 4.78 & 0.01 & 0.18 & 0.36 & 6.80 & 0.03 & 1.45 & -0.07 & -2.68 & 0.22 & 8.91 & -0.48 & -10.59 \\
\hline $\mathrm{Tr}^{*} \mathrm{SH}^{*} \mathrm{PP}$ & -0.10 & -3.81 & 0.10 & 4.01 & -0.05 & -0.40 & 0.35 & 7.77 & 0.09 & 3.25 & -0.13 & -4.02 & 0.30 & 9.80 & -0.52 & -9.96 \\
\hline Tr*SP*PP & -0.11 & -3.79 & 0.15 & 5.44 & -0.18 & -3.32 & 0.46 & 8.40 & 0.05 & 1.80 & -0.07 & -2.48 & 0.22 & 7.38 & -0.53 & -10.05 \\
\hline Tr*ST*PP & 0.02 & 0.34 & 0.12 & 2.99 & -0.03 & -0.29 & 0.38 & 5.29 & 0.07 & 2.98 & -0.07 & -2.29 & 0.25 & 8.99 & -0.48 & -9.51 \\
\hline Tr*SA*PP & 0.03 & 0.77 & 0.13 & 5.14 & -0.18 & -2.12 & 0.39 & 8.23 & 0.03 & 1.24 & -0.11 & -3.77 & 0.23 & 8.14 & -0.52 & -9.67 \\
\hline Tr*SW*PP & -0.03 & -0.77 & 0.15 & 5.10 & -0.14 & -2.07 & 0.39 & 7.18 & 0.02 & 1.01 & -0.08 & -3.10 & 0.20 & 8.46 & -0.49 & -10.26 \\
\hline Tr*YK*PP & 0.08 & 1.33 & 0.17 & 5.84 & 0.00 & 0.00 & 0.43 & 9.27 & 0.00 & 0.09 & 0.01 & 0.20 & 0.20 & 7.46 & -0.41 & -9.41 \\
\hline
\end{tabular}


Appendix 1 (Contd.). Unrestricted model. Trend interaction by region, products and consumption levels

\begin{tabular}{|c|c|c|c|c|c|c|c|c|c|c|c|c|c|c|c|c|}
\hline \multirow[t]{3}{*}{ Regressors } & \multicolumn{4}{|c|}{$\Delta \mathrm{Y}=\Delta \mathrm{ML}$} & \multicolumn{4}{|c|}{$\Delta \mathrm{Y}=\Delta \mathrm{HL}$} & \multicolumn{4}{|c|}{$\Delta \mathrm{Y}=\Delta \mathrm{IM}$} & \multicolumn{4}{|c|}{$\Delta \mathrm{Y}=\Delta \mathrm{IB}$} \\
\hline & \multicolumn{2}{|c|}{ Feb. 99-Apr. 02} & \multicolumn{2}{|c|}{ Jun. 02-Dec. 06} & \multicolumn{2}{|c|}{ Feb. 99-Apr. 02} & \multicolumn{2}{|c|}{ Jun. 02-Dec. 06} & \multicolumn{2}{|c|}{ Feb. 99-Apr. 02} & \multicolumn{2}{|c|}{ Jun. 02-Dec. 06} & \multicolumn{2}{|c|}{ Feb. 99-Apr. 02} & \multicolumn{2}{|c|}{ Jun. 02-Dec. 06} \\
\hline & Coeff. & t-Stat & Coeff. & $\mathrm{t}-$ Stat & Coeff. & t-Stat & Coeff. & $\mathrm{t}$-Stat & Coeff. & t-Stat & Coeff. & t-Stat & Coeff. & t-Stat & Coeff. & $\mathrm{t}$-Stat \\
\hline \multicolumn{17}{|l|}{ Group 3} \\
\hline$\overline{\mathrm{Tr} * \mathrm{EA}^{*} \mathrm{QB}}$ & -0.09 & -1.83 & 0.10 & 4.54 & -0.21 & -3.04 & 0.33 & 7.98 & 0.11 & 2.98 & -0.04 & -1.32 & 0.20 & 7.27 & -0.41 & -11.2 \\
\hline Tr*EM*QB & -0.06 & -1.24 & 0.09 & 4.28 & -0.12 & -1.60 & 0.31 & 7.91 & 0.11 & 3.04 & -0.03 & -1.02 & 0.21 & 8.31 & -0.38 & -11.3 \\
\hline Tr*LD*QB & -0.04 & -0.78 & 0.13 & 4.38 & -0.13 & -1.87 & 0.33 & 7.64 & 0.09 & 3.04 & -0.08 & -2.55 & 0.21 & 8.68 & -0.42 & -10.3 \\
\hline $\mathrm{Tr}^{*} \mathrm{MD} * \mathrm{QB}$ & -0.08 & -1.80 & 0.11 & 4.46 & -0.16 & -2.42 & 0.32 & 7.51 & 0.12 & 2.97 & 0.00 & -0.06 & 0.22 & 8.80 & -0.35 & -9.37 \\
\hline $\mathrm{Tr}^{*} \mathrm{MW}^{*} \mathrm{QB}$ & -0.08 & -2.69 & 0.10 & 3.80 & -0.19 & -3.00 & 0.32 & 7.66 & 0.12 & 3.05 & -0.04 & -1.54 & 0.23 & 8.10 & -0.39 & -9.59 \\
\hline $\mathrm{Tr}^{*} \mathrm{NT} * \mathrm{QB}$ & 0.01 & 0.35 & 0.14 & 5.51 & -0.11 & -1.41 & 0.37 & 7.65 & 0.15 & 3.56 & 0.01 & 0.54 & 0.21 & 8.55 & -0.36 & -9.44 \\
\hline $\mathrm{Tr}^{*} \mathrm{NW}^{*} \mathrm{QB}$ & -0.08 & -2.10 & 0.09 & 3.81 & -0.23 & -3.97 & 0.34 & 5.48 & 0.13 & 3.45 & -0.02 & -0.87 & 0.21 & 8.11 & -0.39 & -11.3 \\
\hline Tr*SE*QB & -0.07 & -1.49 & 0.12 & 4.83 & -0.15 & -2.18 & 0.34 & 7.87 & 0.14 & 3.32 & -0.06 & -1.86 & 0.19 & 7.80 & -0.43 & -9.39 \\
\hline $\mathrm{Tr}^{*} \mathrm{SH}^{*} \mathrm{QB}$ & -0.07 & -2.30 & 0.10 & 3.63 & -0.16 & -3.47 & 0.30 & 7.73 & 0.13 & 3.49 & -0.11 & -3.73 & 0.33 & 9.20 & -0.45 & -9.82 \\
\hline Tr*SP*QB & -0.15 & -5.73 & 0.11 & 3.65 & -0.20 & -3.99 & 0.33 & 6.93 & 0.14 & 3.10 & -0.05 & -1.84 & 0.30 & 8.84 & -0.40 & -9.85 \\
\hline Tr*ST*QB & -0.07 & -1.75 & 0.10 & 4.04 & -0.16 & -2.59 & 0.32 & 8.32 & 0.15 & 3.82 & -0.08 & -2.62 & 0.25 & 8.92 & -0.43 & -9.30 \\
\hline $\mathrm{Tr} * \mathrm{SA} * \mathrm{QB}$ & -0.05 & -1.11 & 0.11 & 4.64 & -0.16 & -2.28 & 0.32 & 7.66 & 0.13 & 3.70 & -0.11 & -3.52 & 0.23 & 9.50 & -0.48 & -9.70 \\
\hline $\mathrm{Tr}^{*} \mathrm{SW} \mathrm{W}^{\mathrm{QB}}$ & -0.09 & -2.60 & 0.08 & 3.40 & -0.19 & -3.38 & 0.32 & 7.42 & 0.12 & 3.40 & -0.06 & -2.43 & 0.22 & 7.62 & -0.41 & -10.1 \\
\hline $\mathrm{Tr}^{*} \mathrm{YK} * \mathrm{QB}$ & -0.01 & -0.21 & 0.15 & 5.76 & -0.08 & -1.22 & 0.34 & 7.78 & 0.13 & 3.40 & -0.01 & -0.21 & 0.22 & 8.81 & -0.36 & -9.26 \\
\hline \multicolumn{17}{|l|}{ Group 4} \\
\hline $\mathrm{Tr}^{*} \mathrm{EA}^{*} \mathrm{DD} \mathrm{D}^{*} \mathrm{~L}$ & 0.05 & 0.87 & 0.01 & 0.58 & -0.04 & -0.43 & 0.04 & 0.93 & -0.06 & -1.77 & -0.02 & -0.68 & -0.04 & -1.67 & -0.04 & -1.49 \\
\hline Tr*EM*DD*L & 0.00 & 0.02 & 0.07 & 2.58 & -0.05 & -0.37 & 0.10 & 2.15 & -0.12 & -3.13 & -0.06 & -1.77 & -0.13 & -4.20 & -0.10 & -3.09 \\
\hline $\operatorname{Tr} * \mathrm{LD} * \mathrm{DD} * \mathrm{~L}$ & 0.04 & 0.69 & 0.02 & 0.74 & 0.00 & -0.01 & 0.03 & 0.71 & -0.08 & -2.36 & -0.05 & -1.65 & -0.11 & -3.35 & -0.08 & -2.19 \\
\hline $\operatorname{Tr} * \mathrm{MD} * \mathrm{DD} * \mathrm{~L}$ & 0.07 & 1.19 & 0.00 & 0.12 & 0.01 & 0.09 & 0.03 & 0.58 & -0.13 & -3.68 & -0.11 & -4.04 & -0.10 & -3.37 & -0.14 & -4.13 \\
\hline Tr*MW*DD*L & 0.02 & 0.36 & -0.03 & -1.02 & -0.05 & -0.52 & 0.00 & 0.08 & -0.05 & -1.12 & -0.02 & -0.92 & -0.04 & -1.05 & -0.04 & -1.19 \\
\hline Tr*NT*DD*L & 0.07 & 1.12 & 0.02 & 0.74 & 0.06 & 0.55 & -0.03 & -0.67 & -0.07 & -1.74 & -0.11 & -3.92 & -0.01 & -0.24 & -0.08 & -2.63 \\
\hline Tr*NW*DD*L & 0.04 & 0.64 & 0.01 & 0.61 & 0.03 & 0.32 & 0.06 & 0.67 & -0.07 & -2.08 & -0.05 & -1.33 & -0.10 & -3.34 & -0.12 & -2.85 \\
\hline Tr*SE*DD*L & 0.11 & 1.45 & 0.02 & 0.92 & 0.02 & 0.19 & 0.05 & 0.95 & -0.19 & -2.66 & -0.05 & -1.72 & -0.13 & -2.03 & -0.06 & -1.63 \\
\hline Tr*SH*DD*L & -0.03 & -0.63 & 0.01 & 0.46 & -0.01 & -0.20 & 0.06 & 1.73 & 0.04 & 1.21 & 0.04 & 1.17 & -0.05 & -1.66 & -0.04 & -0.87 \\
\hline $\operatorname{Tr} * \mathrm{SP} * \mathrm{DD} * \mathrm{~L}$ & 0.06 & 1.94 & -0.03 & -0.85 & 0.02 & 0.46 & 0.00 & -0.08 & -0.04 & -0.89 & -0.01 & -0.41 & -0.05 & -1.55 & -0.05 & -1.30 \\
\hline $\operatorname{Tr} * \mathrm{ST}^{*} \mathrm{DD} * \mathrm{~L}$ & 0.08 & 1.76 & 0.00 & -0.12 & 0.01 & 0.13 & 0.03 & 0.77 & -0.01 & -0.22 & 0.01 & 0.29 & -0.04 & -1.28 & -0.03 & -0.64 \\
\hline Tr*SA*DD*L & 0.00 & 0.03 & -0.01 & -0.25 & 0.01 & 0.09 & 0.03 & 0.78 & -0.03 & -0.69 & -0.01 & -0.19 & -0.07 & -1.73 & -0.05 & -1.11 \\
\hline $\mathrm{Tr}^{*} \mathrm{SW}^{*} \mathrm{DD} \mathrm{D}^{*} \mathrm{~L}$ & 0.05 & 1.49 & 0.03 & 1.64 & 0.00 & -0.03 & 0.03 & 0.85 & -0.11 & -3.02 & -0.05 & -1.57 & -0.11 & -2.60 & -0.09 & -1.94 \\
\hline Tr*YK*DD*L & 0.04 & 0.79 & 0.02 & 0.69 & -0.02 & -0.19 & 0.03 & 0.64 & -0.08 & -2.50 & -0.13 & -4.33 & -0.07 & -3.56 & -0.16 & -4.34 \\
\hline
\end{tabular}




\begin{tabular}{|c|c|c|c|c|c|c|c|c|c|c|c|c|c|c|c|c|}
\hline \multirow[t]{3}{*}{ Regressors } & \multicolumn{4}{|c|}{$\Delta \mathrm{Y}=\Delta \mathrm{ML}$} & \multicolumn{4}{|c|}{$\Delta \mathrm{Y}=\Delta \mathrm{HL}$} & \multicolumn{4}{|c|}{$\Delta \mathrm{Y}=\Delta \mathrm{IM}$} & \multicolumn{4}{|c|}{$\Delta \mathrm{Y}=\Delta \mathrm{IB}$} \\
\hline & \multicolumn{2}{|c|}{ Feb. 99-Apr. 02} & \multicolumn{2}{|c|}{ Jun. 02-Dec. 06} & \multicolumn{2}{|c|}{ Feb. 99-Apr. 02} & \multicolumn{2}{|c|}{ Jun. 02-Dec. 06} & \multicolumn{2}{|c|}{ Feb. 99-Apr. 02} & \multicolumn{2}{|c|}{ Jun. 02-Dec. 06} & \multicolumn{2}{|c|}{ Feb. 99-Apr. 02} & \multicolumn{2}{|c|}{ Jun. 02-Dec. 06} \\
\hline & Coeff. & t-Stat & Coeff. & t-Stat & Coeff. & t-Stat & Coeff. & $\mathrm{t}-\mathrm{Stat}$ & Coeff. & t-Stat & Coeff. & $\mathrm{t}-\mathrm{Stat}$ & Coeff. & t-Stat & Coeff. & t-Stat \\
\hline Group 5 & & & & & & & & & & & & & & & & \\
\hline 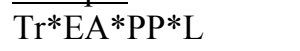 & -0.06 & -1.02 & 0.00 & 0.06 & 0.05 & 0.51 & 0.07 & 1.12 & 0.01 & 0.32 & -0.03 & -0.91 & 0.00 & 0.08 & 0.03 & 1.07 \\
\hline $\operatorname{Tr} * \mathrm{EM}^{*} \mathrm{PP} * \mathrm{~L}$ & -0.08 & -0.78 & 0.04 & 1.37 & 0.05 & 0.27 & 0.15 & 2.99 & -0.03 & -0.77 & -0.05 & -1.34 & -0.03 & -1.12 & -0.02 & -0.56 \\
\hline $\operatorname{Tr} * \mathrm{LD} * \mathrm{PP} * \mathrm{~L}$ & -0.02 & -0.25 & 0.01 & 0.25 & 0.03 & 0.29 & 0.02 & 0.29 & 0.00 & -0.31 & -0.03 & -0.87 & -0.01 & -0.40 & 0.01 & 0.34 \\
\hline Tr*MD*PP*L & -0.12 & -2.23 & 0.01 & 0.86 & 0.06 & 0.45 & -0.05 & -0.94 & -0.01 & -0.80 & -0.03 & -1.64 & -0.02 & -1.29 & 0.02 & 0.74 \\
\hline Tr*MW*PP*L & 0.00 & 0.07 & 0.02 & 1.29 & 0.13 & 2.20 & 0.09 & 2.12 & -0.02 & -0.86 & -0.01 & -0.59 & -0.02 & -0.52 & 0.03 & 0.75 \\
\hline Tr*NT*PP*L & -0.04 & -0.69 & 0.00 & 0.18 & 0.01 & 0.08 & -0.08 & -1.63 & -0.03 & -0.83 & -0.02 & -0.97 & -0.01 & -0.18 & 0.05 & 1.80 \\
\hline Tr*NW*PP*L & 0.02 & 0.31 & 0.03 & 1.30 & 0.02 & 0.08 & 0.04 & 0.55 & -0.02 & -0.80 & -0.06 & -2.03 & 0.00 & -0.02 & 0.00 & -0.10 \\
\hline Tr*SE*PP*L & 0.05 & 0.58 & 0.03 & 0.90 & 0.17 & 2.22 & 0.08 & 0.88 & -0.07 & -1.21 & -0.04 & -1.16 & -0.01 & -0.88 & 0.07 & 2.00 \\
\hline $\mathrm{Tr}^{*} \mathrm{SH}^{*} \mathrm{PP} * \mathrm{~L}$ & 0.03 & 1.74 & 0.00 & 0.10 & 0.06 & 0.28 & 0.04 & 1.32 & -0.04 & -1.67 & 0.02 & 0.48 & -0.01 & -0.65 & 0.05 & 1.05 \\
\hline Tr*SP*PP*L & 0.10 & 2.97 & 0.00 & 0.09 & 0.19 & 4.05 & 0.00 & 0.04 & -0.03 & -1.55 & 0.00 & 0.10 & -0.01 & -0.56 & 0.05 & 1.18 \\
\hline $\mathrm{Tr} * \mathrm{ST} * \mathrm{PP} * \mathrm{~L}$ & 0.00 & -0.02 & 0.03 & 0.83 & 0.00 & -0.01 & 0.04 & 0.58 & -0.01 & -0.27 & 0.00 & 0.09 & -0.01 & -0.38 & 0.05 & 1.16 \\
\hline $\operatorname{Tr} * \mathrm{SA} * \mathrm{PP} * \mathrm{~L}$ & -0.04 & -1.10 & 0.01 & 0.51 & 0.20 & 2.53 & 0.07 & 1.74 & -0.01 & -0.81 & 0.01 & 0.21 & -0.01 & -0.28 & 0.06 & 1.27 \\
\hline $\operatorname{Tr} * \mathrm{SW}^{*} \mathrm{PP} * \mathrm{~L}$ & 0.08 & 1.46 & 0.02 & 0.66 & 0.20 & 2.43 & 0.02 & 0.37 & -0.03 & -1.71 & -0.05 & -2.00 & -0.02 & -1.13 & 0.00 & -0.06 \\
\hline $\mathrm{Tr}^{*} \mathrm{YK}^{*} \mathrm{PP} * \mathrm{~L}$ & -0.02 & -0.25 & 0.00 & -0.08 & -0.01 & -0.11 & -0.06 & -1.50 & 0.00 & 0.07 & -0.04 & -1.47 & -0.01 & -0.23 & 0.00 & -0.06 \\
\hline \multicolumn{17}{|l|}{ Group 6} \\
\hline Tr*EA* $\mathrm{QB} * \mathrm{~L}$ & -0.06 & -1.05 & 0.07 & 2.49 & -0.01 & -0.11 & 0.09 & 1.90 & -0.05 & -1.72 & -0.06 & -1.67 & -0.10 & -2.81 & -0.08 & -2.34 \\
\hline Tr*EM*QB*L & -0.02 & -0.30 & 0.09 & 3.29 & -0.08 & -0.78 & 0.13 & 3.40 & -0.09 & -2.83 & -0.07 & -2.12 & -0.13 & -4.20 & -0.13 & -3.42 \\
\hline Tr*LD*QB*L & -0.04 & -0.81 & 0.05 & 1.60 & -0.05 & -0.66 & 0.08 & 1.58 & -0.07 & -2.27 & -0.04 & -1.14 & -0.10 & -3.77 & -0.08 & -2.29 \\
\hline $\operatorname{Tr}^{*} \mathrm{MD}^{*} \mathrm{QB} * \mathrm{~L}$ & 0.07 & 1.28 & 0.07 & 2.46 & 0.02 & 0.26 & 0.08 & 2.03 & -0.17 & -3.76 & -0.09 & -3.97 & -0.15 & -4.82 & -0.12 & -3.17 \\
\hline $\mathrm{Tr}^{*} \mathrm{MW} \mathrm{W}^{*} \mathrm{QB} * \mathrm{~L}$ & 0.01 & 0.23 & 0.01 & 0.38 & -0.02 & -0.21 & 0.02 & 0.43 & -0.07 & -2.60 & -0.03 & -1.02 & -0.07 & -2.83 & -0.04 & -1.12 \\
\hline Tr*NT*QB*L & 0.01 & 0.18 & 0.02 & 0.56 & 0.02 & 0.22 & 0.01 & 0.18 & -0.04 & -1.65 & -0.08 & -3.26 & 0.00 & -0.06 & -0.07 & -2.03 \\
\hline $\operatorname{Tr}^{*} \mathrm{NW}^{*} \mathrm{QB} * \mathrm{~L}$ & 0.01 & 0.14 & 0.05 & 1.96 & 0.06 & 0.81 & 0.10 & 1.17 & -0.07 & -2.83 & -0.05 & -1.44 & -0.12 & -3.97 & -0.12 & -3.35 \\
\hline Tr*SE*QB*L & 0.04 & 0.61 & 0.10 & 3.23 & -0.06 & -0.72 & 0.08 & 1.43 & -0.12 & -3.34 & -0.07 & -2.28 & -0.11 & -3.58 & -0.06 & -1.54 \\
\hline $\mathrm{Tr}^{*} \mathrm{SH}^{*} \mathrm{QB} * \mathrm{~L}$ & 0.00 & 0.05 & 0.03 & 0.90 & -0.05 & -0.89 & 0.05 & 1.71 & -0.03 & -1.04 & -0.01 & -0.22 & -0.10 & -2.98 & -0.08 & -1.83 \\
\hline $\mathrm{Tr} * \mathrm{SP}^{*} \mathrm{QB} * \mathrm{~L}$ & 0.06 & 1.53 & 0.04 & 1.01 & 0.00 & -0.01 & 0.04 & 0.96 & -0.06 & -1.67 & -0.01 & -0.38 & -0.09 & -3.02 & -0.05 & -1.34 \\
\hline $\mathrm{Tr}^{*} \mathrm{ST}^{*} \mathrm{QB} * \mathrm{~L}$ & -0.01 & -0.23 & 0.04 & 1.33 & -0.04 & -0.46 & 0.07 & 1.55 & -0.04 & -1.68 & -0.02 & -0.77 & -0.10 & -3.23 & -0.07 & -1.50 \\
\hline $\operatorname{Tr} * \mathrm{SA}^{*} \mathrm{QB} * \mathrm{~L}$ & 0.02 & 0.30 & 0.00 & -0.17 & -0.04 & -0.51 & 0.05 & 1.53 & -0.09 & -2.42 & -0.03 & -0.95 & -0.14 & -4.64 & -0.10 & -1.93 \\
\hline $\mathrm{Tr}^{*} \mathrm{SW} \mathrm{W}^{*} \mathrm{QB} * \mathrm{~L}$ & -0.01 & -0.23 & 0.07 & 2.38 & 0.00 & -0.03 & 0.08 & 2.05 & -0.10 & -3.63 & -0.05 & -1.87 & -0.11 & -3.69 & -0.09 & -2.48 \\
\hline $\mathrm{Tr}^{*} \mathrm{YK}^{*} \mathrm{QB} * \mathrm{~L}$ & -0.03 & -0.46 & 0.03 & 1.27 & -0.13 & -1.50 & 0.07 & 1.89 & -0.05 & -2.00 & -0.10 & -3.59 & -0.06 & -3.31 & -0.14 & -3.36 \\
\hline R-squared & 0.17 & & 0.28 & & 0.14 & & 0.22 & & 0.18 & & 0.23 & & 0.28 & & 0.30 & \\
\hline Adjusted R-squared & 0.12 & & 0.25 & & 0.08 & & 0.18 & & 0.13 & & 0.19 & & 0.23 & & 0.27 & \\
\hline S.E. of regression & 2.70 & & 3.26 & & 5.47 & & 6.22 & & 1.84 & & 3.45 & & 1.86 & & 4.35 & \\
\hline F-statistic [ $p$-value $]$ & 3.23 & {$[0.00]$} & 8.35 & {$[0.00]$} & 2.50 & {$[0.00]$} & 6.02 & {$[0.00]$} & 3.51 & {$[0.00]$} & 6.34 & {$[0.00]$} & 5.99 & {$[0.00]$} & 9.15 & {$[0.00]$} \\
\hline
\end{tabular}

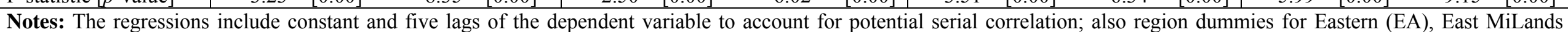

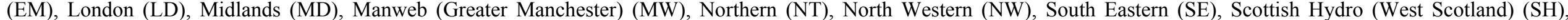

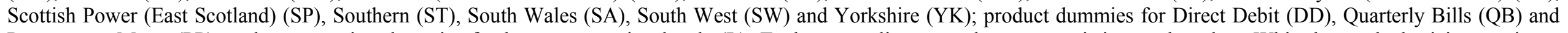

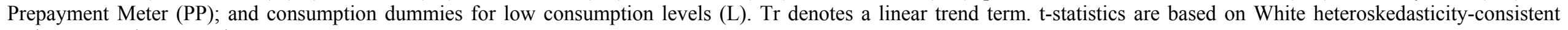
variance-covariance matrix. 